Hacettepe University Graduate School of Social Sciences

Department of Psychology

Master of Science in General Psychology

ECOCULTURAL PERSPECTIVE IN LEARNING DISABILITY: FAMILY SUPPORT RESOURCES, VALUES, CHILD PROBLEM BEHAVIORS

Suzan Çen

Master's Thesis

Ankara, 2016 

ECOCULTURAL PERSPECTIVE IN LEARNING DISABILITY: FAMILY SUPPORT RESOURCES, VALUES, CHILD PROBLEM BEHAVIORS

Suzan Çen

Hacettepe University Graduate School of Social Sciences

Department of Psychology

Master of Science in General Psychology

Master's Thesis

Ankara, 2016 


\section{ACCEPTANCE AND APPROVAL}

The jury finds that Suzan Çen has on the date of 15.06 .2016 successfully passed the defense examination and approves his/her Master's Thesis titled "Ecocultural Perspective In Learning Disability: Family Support Resources, Values, Child Problem Behaviors".

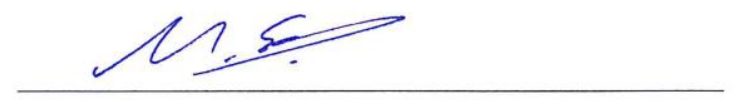

Pof. Dr. Melike Sayıl (Başkan)

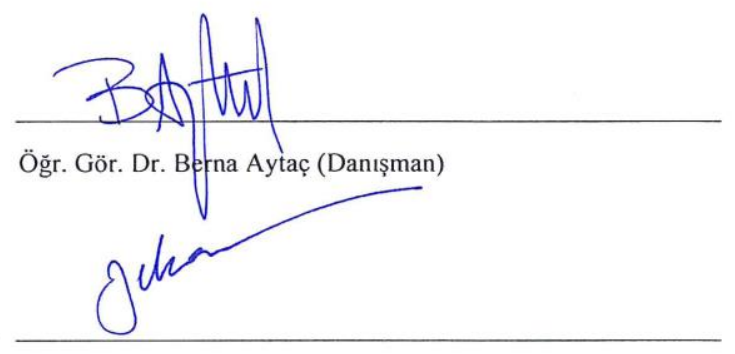

Pof. Dr. Zehra Uçanok

Yukarıdaki imzaların adı geçen öğretim üyelerine ait olduğunu onaylarım.

Prof. Dr. Sibel Bozbeyoğlu

Enstitü Müdürü 


\section{DECLARATION}

I promise that my thesis/report is completely my own work and that I have provided a source for every quotation and citation. I give permission for paper and digital copies of my thesis/report to be kept in Hacttepe University's Graduate School of Social Sciences' archives under the conditions indicated below:

$\square$ My thesis/Report can be accessed in full from any location.

$\square \quad$ My thesis/Report can only be accessed from Hacettepe University premises.

\. I do not want my thesis/report to be accessed until 1 year later. After this amount of time if I have not applied to an extension of time, my thesis/report can be accessed in full from any location.

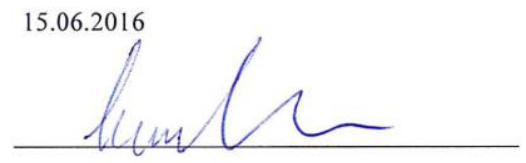

Suzan ÇEN 
Love children,

Love humanity,

Love the world... 


\section{ACKNOWLEDGEMENTS}

I would like to offer my appreciation and thanks to all people that helped me in this journey. Firstly, I would like to offer my gratitude to my dear supervisor $\mathrm{PhD}$. Berna Aytaç. She always supported me with her all of patience, experience, knowledge and guided me with her feedbacks. She always advised me to believe myself in order to do better and better. The most important thing is that I always received a warm welcome and smiling face that encouraged me throughout this hard work.

I would like to give my greatest thanks to Prof. Dr. Melike Sayıl, Prof. Dr. Zehra Uçanok, Asst. Prof. Dr. Athanasios Mouratidis and Assoc. Prof. Dr. Sait Uluç, for insightful and valuable feedbacks and suggestions to my research and also supporting me during my study years.

I would like to give my greatest appreciation to Msc. Meral Keighobadi, Aslı Karagöz Uzun, Tayfur Mert, Mürsel Artur, Ayşegül Yanar Kılınç, Görkem Kılınç for their priceless and gentle help and supports during the data collection.

I would like to thank to my family and my love; my supportive parents, and my precious sister and brothers for their patience through my life. The most beautiful thing is that I know that they will always love me and continue to give support.

In addition, I thank to all the children, the mothers, and special education teachers who participated in this study. I wish I would make a little difference into their lives to make them understand not fears but happiness better than all others.

Last but not least, I would like to thank to all of the people, who contributed this process in one way or another, but whose names I could not list here. 


\begin{abstract}
ÇEN, S. Ecocultural Perspective in Learning Disability: Family Support Resources, Values, Child Problem Behaviors, Master's Thesis, Ankara, 2016.

Ecocultural theory assumes that familial factors such as family support resources and cultural factors such as values organize, and shape family activities, and influence child developmental outcomes of disabled children. Therefore, in the current study, it was aimed to assess the interaction between familial and cultural factors with child problem behaviors within the perspective of ecocultural theory in learning disabled children aged between 7-14.
\end{abstract}

In total, 90 learning disabled children' mothers and teachers were participated in this study. They filled Family Support Scale, Portrait Values Questionnaire, Specific Learning Disability Symptom Check List (Teacher Form) and Child Behavior Problem Scale (Teacher Form) and Social-demographical Form. In analysis, Pearson correlation, regression analysis and Hayes' (2013) moderation analysis were conducted. After testing relationship between support resources and problem behaviors, support analyses were repeated after including learning disability level.

For support resources, only informational support marginally predicted internalizing problems when learning disability level was controlled, but when excluded from the model, it significantly predicted. Caregiving and emotional significantly, and financial support marginally predicted externalizing problems when learning disability level was excluded, but become non-significant after controlling for learning disability level. However, unexpectedly, the interaction of emotional support and learning disability level marginally predicted externalizing problems. 
For values, when mothers have high scores both conservation and openness to change values' scale, the internalizing problems tended to be lowest in learning disabled children after learning disability level was controlled.

In sum, the findings revealed that ideas about child development depend on cultural and individual factors, and a culturally sensitive understanding of child behaviors can guide researchers in developing more effective intervention programs, particularly in learning disabled children.

Keywords: learning disability, perceived family support, values, internalizing problems, externalizing problems. 


\section{ÖZET}

ÇEN, S. Ekokültürel Bakışla Öğrenme Gü̈lüğü: Ailenin Destek Kaynaklarl, Değerler, Çocuğun Davranış Sorunları, Yüksek Lisans Tezi, Ankara, 2016.

Ekokültürel kuram ailenin destek kaynakları gibi ailesel faktörler, ya da değerler gibi kültürel faktörlerin ailenin aktivitelerini organize ettiğini ve şekillendirdiğini, engelli çocuğun gelişimsel çıktılarını etkilediğini varsayar. Bu nedenle, bu çalışmada ailesel ve kültürel faktörlerin çocuğun davranış sorunlarıyla olan etkileşiminin ekokültürel kuram çerçevesinde 7-14 yaş arası öğrenme güçlüğü olan çocuklarda incelenmesi hedeflenmiştir.

Toplamda 90 öğrenme güçlüğü olan çocuğun annesi ve öğretmeni çalı̧maya katıldı. Katılımcılar Aile Destek Ölçeği, Portre Değerler Ölçeği, Özel Öğrenme Güçlüğü Semptom Kontrol Listesi (Öğretmen formu) ve Problem Davranış Ölçeği (Öğretmen formu) ve sosyodemografik formunu doldurdu. Analizlerde, Pearson korelasyon analizi, regresyon analizi ve Hayes'in (2013) düzenleyici değişken analizi yapıldı. Bu çalışmada destek kaynakları ile problem davranışları arasındaki ilişkiye bakıldıktan sonra, sosyal destek analizleri öğrenme güçlüğü düzeyi kontrol edilerek tekrarlandı.

Sosyal destek ile ilgili olarak, yalnızca algılanan bilgi desteği, öğrenme güçlüğü düzeyi kontrol edildiğinde içselleştirme sorunlarını marjinal olarak, edilmediğinde anlamlı olarak yordamıştır. Ancak algılanan bakım veren desteği ve duygusal destek anlamlı olarak, ve finansal destek ise marjinal olarak dışsallaştırma sorunlarını yordarken, öğrenme güçlüğü düzeyi kontrol edildiğinde iliş̧i anlamsız hale gelmiş̧ir. Ancak beklenmedik şekilde, duygusal destek ile öğrenme güçlüğü düzeyinin etkileşimi dışsallaştırma sorunlarını marjinal olarak yordamıştır.

Değerlerle ilgili olarak, öğrenme güçlüğü düzeyi kontrol edildiğinde, hem muhafazacılık hem de yeniliğe açıklık değerler ölçeğinden yüksek puan alan 
ebeveynlerin çocuklarında içselleştirme sorunlarının en düşük olma eğiliminde olduğu bulunmuştur.

Sonuç olarak, çocuğun gelişiminin kültürel ve bireysel faktörlerden etkilendiği, kültürel anlayışın özellikle öğrenme güçlüğü olan çocuklara yönelik etkili müdahale programları geliştirmede araştırmacılara yol gösterebileceği görülmüştür.

Anahtar Sözcükler: öğrenme güçlüğü, algılanan aile desteği, değerler, içselleştirme sorunları, dışsallaştırma sorunları. 
TABLE OF CONTENTS

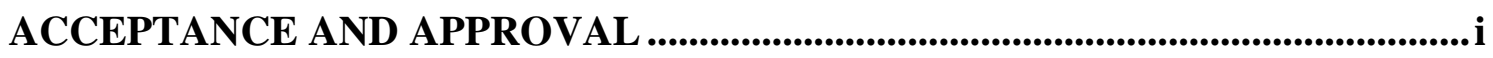

DECLARATION ..........................................................................................................

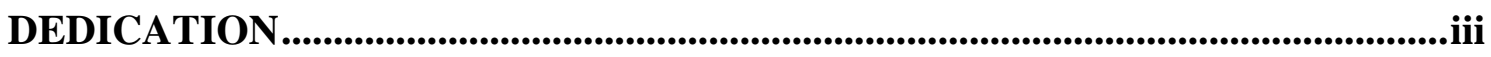

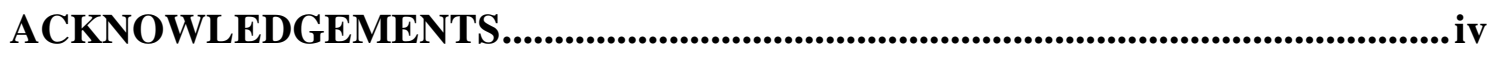

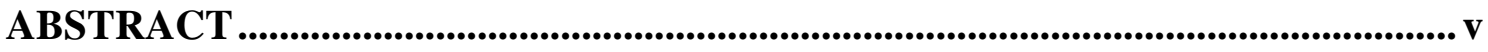

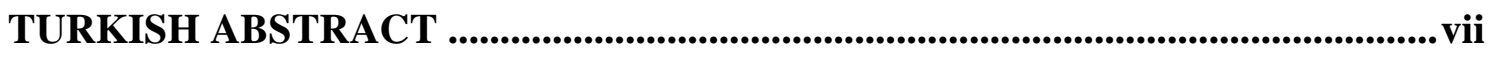

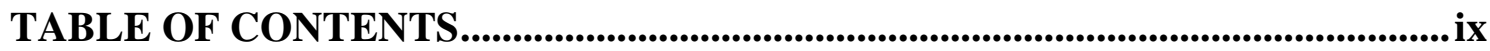

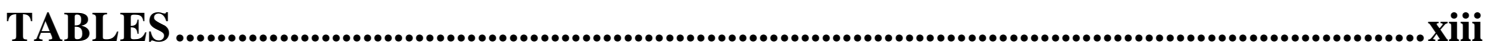

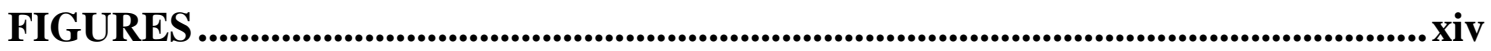

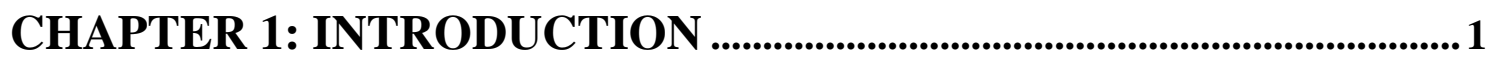

1.1. LEARNING DISABILITY ....................................................................... 3

1.1.1. Diagnosis, Subtypes and Treatment of Learning Disability .......................... 3

1.1.2. Family and Learning Disability Children ................................................ 5

\subsection{THEORETICAL PERSPECTIVE IN CHILDHOOD}

DISABILITY ...................................................................................................

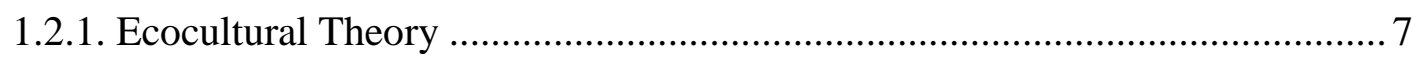

1.2.2. Culture, Family and Disability in Ecocultural Theory ................................. 8

\subsection{THE ASSESSED FACTORS RELATED TO DISABLED}

CHILDREN IN ECOCULTURAL THEORY .............................................10

1.3.1. Family’s Social Support Resources and Disability..................................... 10

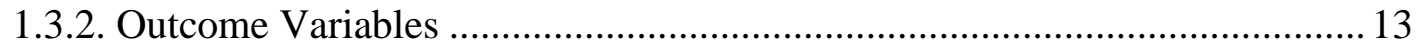

1.3.2.1. Learning Disabled Children and Problem Behaviors ....................... 13 
1.3.2.2. Internalizing Problems and Externalizing Problems in Learning

Disability. 14

1.3.3. The Relationship between Perceived Social Support Resources and Child Problem Behaviors.

1.3.4. Values 18

1.3.4.1. Parenting and Values 20

1.3.5. The Relationship between Values and Perceived Social Support 22

1.3.6. The Relationship between Values and Child Problem Behaviors 24

1.3.7. The Relationship between Learning Disability Level and Child Problem

Behaviors .25

1.4. THE PRESENT STUDY 26

CHAPTER 2: METHOD 28

2.1. PARTICIPANTS .28

2.2. MEASUREMENTS 30

2.2.1. Social-Demographic Information Form 30

2.2.2. Family Support Scale 30

2.2.3. Portrait Values Questionnaire (PVQ) 31

2.2.4. Specific Learning Disability Symptom Check List (Teacher Form) 32

2.2.5. Child Behavior Problem Scale (Teacher Form) 33

2.3. PROCEDURE 33 
3.1.1. Correlations between Demographical Variables and Study Variables

3.1.2. Correlations between Predictor Variables

3.1.3. Correlations between Predictor and Outcome Variables. 38

\subsection{REGRESSION ANALYSES}

3.3.1. Hierarchical Regression for Perceived Social Support Resources and Internalizing Problems

3.3.1.1. Results for Internalizing Problems without Controlling for Learning

Disability Level

3.3.1.2. Results for Internalizing Problems after Controlling for Learning

Disability Level 41

3.3.2. Hierarchical Regression for Perceived Social Support Resources and Externalizing Problems 42

3.3.2.1. Results for Externalizing Problems without Controlling for Learning

Disability Level. 42

3.3.2.2. Results for Externalizing Problems after Controlling for Learning Disability Level. 46

3.3.3. Hierarchical Regression for Values and Perceived Social Support Resources 49

3.3.4. Hierarchical Regression for Values and Internalizing Problems 50

3.3.5. Hierarchical Regression for Values and Externalizing Problems. .53

CHAPTER 4: DISCUSSION .54

\subsection{EVALUATION OF CORRELATIONS BETWEEN STUDY}




\subsection{EVALUATION OF PREDICTORS OF CHILD PROBLEM BEHAVIORS} .56

4.2.1. Findings for Perceived Social Support Resources and Internalizing Problems 56

4.2.2. Findings for Perceived Social Support Resources and Externalizing Problems 57

4.2.3. Findings for Values. 60

4.2.3.1. Evaluation of the Findings about Values and Perceived Social Support Resources 61

4.2.3.2. Evaluation of the Findings about Values and Internalizing Problems 61

4.2.3.3. Evaluation of the Findings about Values and Externalizing Problems 62

4.3. LIMITATIONS AND SUGGESTIONS ...............................................63

4.4. IMPLICATION .....................................................................................64

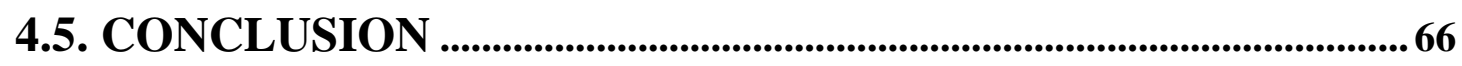

REFRENCES ..............................................................................................67

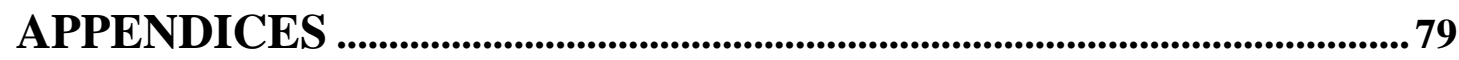

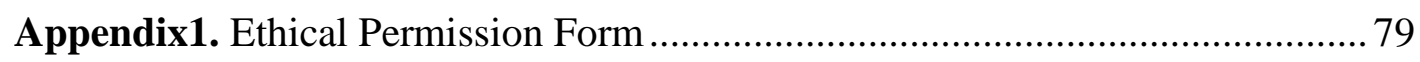

Appendix 2. Dissertation Originality Report ................................................. 80 


\section{TABLES}

Table 1. The Mean and Standard Deviation of Study Variables..................................... 36

Table 2. Bivariate Correlations between the Study Variables ........................................ 39

Table 3. Summary of Hierarchical Regression Analysis for Perceived Informational Support Predicting Internalizing Problems (not controlling for learning disability level

Table 4. Summary of Hierarchical Regression Analysis for Perceived Informational Support Predicting Internalizing Problems (controlling learning for disability level).

Table 5. Summary of Hierarchical Regression Analysis for Perceived Emotional Support Resources Predicting Externalizing Problems (not controlling for learning disability level)

Table 6. Summary of Hierarchical Regression Analysis for Perceived Caregiving Support Resources Predicting Externalizing Problems (not controlling for learning disability).

Table 7. Summary of Hierarchical Regression Analysis for Perceived Financial Support Resources Predicting Externalizing Problems (not controlling for learning disability level). 46

Table 8. Summary of Hierarchical Regression Analysis for Perceived Emotional Support Resources Predicting Externalizing Problems (controlling for learning disability level)...... 48

Table 9. Summary of Hierarchical Regression Analysis for Mothers' Values Predicting Internalizing Problems ..... 


\section{FIGURES}

Figure 1. Percentage of Education Level of Mothers .....................................................29

Figure 2. Percentage of Perceived Income Level of Mothers ......................................2 29

Figure 3. The Interaction between Child Learning Disability Level, Mother

Perceived Emotional Support and Externalizing Problems ........................... 49

Figure 4. The Interaction between Mothers' Values and Internalizing Problems ...........53 


\section{CHAPTER I}

\section{INTRODUCTION}

"All the world's a stage, and all the men and women merely players;" as William Shakespeare said. In this stage, we, players, are the product of both what we bring from our origin and how we perform throughout this story, hence it is an art. This story starts from the conception and continues through the life span with growth and decline (Santrock, 2011). This is called development, a combined product of biological, social, emotional and cognitive changes in the life span, also refers to the process in which the child matures (Keenan \& Evans, 2009; Williamson \& Slye, 2002). The changes occur in the physiology, thought, or behavior of the individual as a result of interaction between these individual characteristics and environmental influences over time (Craig, 1999). However, sometimes in this story, non-normative life events such as difficulties or disabilities occur that effect the individual.

Learning disability is one of these non-normative life events that children are diagnosed usually after starting primary school. Children with learning disability face different developmental outcomes due to both biological (e.g. "neurocognitive and adaptive deficits associated with a significant disturbance of the white matter in the right hemisphere") (Antshel \& Joseph, 2006), and environmental factors (e.g. going to special education center or participating in inclusive classrooms) (Lyytinen et al., 2001). Therefore, although learning disability has biological origins, it is also affected by the context that the child is embedded in (Keogh, Gallimore, \& Weisner, 1997). For example, families' cohesion, adaptability, support resources were found to influence the developmental outcomes of the learning disabled children (Lanchaster, 2001). Thus, it is emphasized that studying learning disabled children's familial and environmental characteristics contribute to the understanding of the specific influences of contexts (e.g. family, neighborhood, and school experiences) on child development (Bauminger \& Kimhi-Kind, 2008). 
A review of the literature shows that many researchers examined the influences of contextual factors on learning disabled children including socio-emotional level (AlYagon, 2012), academic functioning (Al-Yagon \& Mikulincer, 2004), and close relations (Bonifacci, Storti, Tobia, \& Suardi, 2015). Although there have been many studies examined the effect of contextual factors on learning disability, there are virtually limited studies that combine the influence of different factors such as familial and cultural factors.

Ecocultural theory (Weisner, 1997; 2002a; 2002b) assumes that familial factors (e.g. family specific support resources) and cultural factors (e.g. values) organize and shape family activities, and influence child developmental outcomes such as child daily living activities, communication skills and developmental status of disabled children (Bernheimer, Gallimore, \& Weisner, 1990; Weisner, 2002b). Taken together, the research presented here was driven by the motivation to incorporate familial and cultural factors in learning disabled children problem behaviors within the perspective of ecocultural theory.

Although there are studies investigated learning disabled children problem behaviors (Batum \& Öktem, 2011), the importance of social support (Özsoy, Özkahraman, \& Çall1, 2006) and the relation between social support and mothers' stress level (Atalay, 2013), to authors' knowledge the current study is the first study that assesses the effect of both specific support resources and values on learning disabled child behaviors with ecocultural perspective in Turkey.

Life is not always simple and straightforward, and it is with the complexities. Learning disability is a diagnosis that makes both children's and their families' lives challenging and complicated. Thus, in this study, it is expected to see how the familial and cultural factors differentially influence child problem behaviors.

In the following, four chapters will be presented. The introduction part will be presented in chapter 1. In this part, the contextual factors related to disabled children in ecocultural theory, families' social support resources, problem behaviors, and values 
will be discussed. In the second chapter, characteristics of the participants, materials used in the study, and the procedure will be explained. Finally, in the last two chapters, results and discussion along with limitations and suggestions, implications, and the conclusion will be presented.

\subsection{LEARNING DISABILITY}

According to National Joint Committee on Learning Disabilities (1997), "The term 'learning disabilities' refers to a heterogeneous group of disorders manifested by significant difficulties in the acquisition and use of listening, speaking, reading, writing, reasoning, and/or mathematical abilities" (as cited in Heiman \& Berger, 2008). Learning disability is a biologically originated, neurodevelopmental disorder that demonstrates cognitive abnormalities, impairments in verbal and nonverbal information processing of brain, and/or disruption in processing abilities of individuals (DSM-5, 2013; Goldstein, 2011; Raghavan \& Patel, 2005).

Learning disability effects $5 \%$ to $15 \%$ of school age children, $4 \%$ of adults in the world (DSM-5, 2013; Goldstein, 2011). According to official statistics, only in Istanbul, 5\% of school age children were diagnosed as learning disabled (Özkardeş, 2011), and it was seen 2 to 3 times more in boys (DSM-5, 2013; MEB, 2007). Therefore, due to considerable amount of children that are affected by learning disability, assessing these children and their families become imperative for both increasing the understanding of their development and quality of services offered to them.

\subsubsection{Diagnosis, Subtypes and Treatment of Learning Disability}

According to DSM-5 (2013), learning disability has 4 criteria. The first criteria is that there should be at least one difficulty in learning or using academic skills such as reading, writing or mathematics with the onset of formal education. It should be present for at least 6 months (DSM-5, 2013). Besides, there should be no recovery and no catching up with the peers in spite of taking extra help at home or school. These children mainly require special teaching methods for improvement. 
The second criterion is that the child's performance in academic abilities fall behind average for their age (DSM-5, 2013). That interferes with child's academic life. For example, these children take low grades or ratings in school works relative to their peers.

Another diagnosis criterion is that although the learning disability is mostly apparent in the early years of the school, it can have a latent effect. It means that disability may not be apparent until later school years because learning demands increase and exceed the individual's limited capacities during especially later school years (DSM-5, 2013).

The last criterion is that the problem is "specific" and independent of intellectual impairment or developmental delay. Learning disability could be also seen in gifted children. So, it is not associated with intellectual ability (Naglieri \& Goldstein, 2011).

The subtypes of learning disability have been defined in DSM-5 (APA, 2013). The first one is reading problem called as dyslexia. In dyslexia, the child reading speed and fluency are worse than their peers and s/he has problems in reading comprehension. The next problem is writing problems called as dysgraphia. The child has difficulties in spelling, grammar, punctuation, and organization problems in writing a text. The last one is the difficulties in math and arithmetic called as dyscalculia. The child has difficulties in understanding numbers, calculation, mathematical reasoning, problem solving and remembering arithmetic (APA, 2013). In the current study, learning disability was included as a composite score in the analyses, including difficulties in reading, writing, mathematics, nonverbal and verbal language.

Regarding to the treatment of learning disability, children usually need help in academic, behavioral and social domains. More commonly, special education and specific education techniques are used for the improvement of academic abilities (Betts, 2011). However, in complex or severe conditions, multimodal treatments that combine pharmacological, behavioral, and psychological interventions are also used. Also, when learning disability is comorbid with attention deficiency and hyperactivity, cognitive and behavioral therapy are applied in the treatment (Betts, 2011). 
Age or developmental period appropriate interventions are also crucial. To illustrate, gaining academic skills and management of behavioral problems, if there any, may be very crucial during childhood. However, by the adolescence, these children should acquire abilities that they will use in adulthood such as self-protection, management of time and money, taking responsibility, having goals, awareness of the disability and their rights (Betts, 2011). Especially, in young adulthood, dealing with the disability in both family and work life become important for their life quality.

As a whole, learning disability is more salient with the onset of formal education, each child can show different patterns of difficulty, and multimodal interventions can be needed in the treatment process. Characteristics that are unique to the different developmental periods become important and should also be taken into consideration. As diagnosis is taken with the onset of formal education, family characteristics would be critical in this period. Therefore, ages between 7 and 14 was chosen in the current study.

\subsubsection{Family and Learning Disabled Children}

Learning disability, with its diagnosis and treatment process, is an impairment that effects an individual's life span development. With disability, child's necessities, families' needs, well-being, resources, activities, routines and qualities are also influenced (Lancaster, 2001). Given that, it was demonstrated that family was perceiving the disability as a source of stressor, and experiencing more stress than families without a learning disabled child (Antshel \& Joseph, 2006). Similarly, Herring et al., (2006) claimed that compared with fathers, all mothers reported significantly more stress in relation to parenting their disabled child because mothers' generally takes all care of the child. In these families, maternal stress was found to be associated with child's problem behaviors (Antshel \& Joseph, 2006; Herring et al., 2006). Since, Hastings (2002) proposed that stressful parents developed certain parenting behaviors (e.g. using more control) and they tended to reinforce the child's problem behaviors. Nevertheless, Contwell, Muldon and Gallgher (2014) demonstrated the significance of social support on decreasing stress level and increasing physical health of the caregiver. 
Although disabled child is a stressful responsibility for the caregivers, individual resources such as perceived social support moderate the relation between stress and physical health. Thus, social support is a protective factor for disabled children's mothers.

More broadly, as family is nested in a broader cultural context, relevant cultural characteristics should be also taken into account in order to understand family reactions to disability. The studies including culture emphasizes that families' ecocultural factors such as values, beliefs, socioeconomic level, ethnicity were likely to influence learning disabled families' adaptation, child development and behavioral problems (Antshel \& Joseph, 2006; Keogh \& Weisner, 1993). For instance, literacy and academic achievement are mainly reinforced features in Western cultures, so the criteria for mental capacities or learning disability in Western cultures are most likely to vary from agricultural societies (Keogh et al., 1997).

In conclusion, analyzing the families of learning disabled children within the embedded culture could lead to understand these families and their children's life in a broader picture and help to shape comprehensive interventions for these children and their families (Lynch \& Hanson, 1996). Thus, it was aimed to analyze the disability with ecocultural factors and in the next section ecocultural theory was discussed as the starting point.

\subsection{THEORETICAL PERSPECTIVE IN CHILDHOOD DISABILITY}

Bernheimer et al. (1990) criticized the previous studies investigating disabled children and their families. These studies included mostly univariate variables, distal measurements of family characteristics, and were pathology-oriented (Bernheimer et al., 1990). In other words, studies mostly had no theory specified for studying families with handicapped children (e.g. family systems theory), and do not include variables about family structure, interactions, functions, lifestyle, and are mainly centered around pathology of the child. 
On the contrary, new approaches integrated social, ecological, cultural, adaptational and family dimensions of the disability (Dunst, Leet, \& Trivette, 1988; Nihira, Weisner, \& Bernheimer, 1994; Phenice, Griffore, Hakoyama, \& Silvey, 2009). These new social and ecological views trivialized old approaches, conceptualized the disability as a multidimensional issue and guided the development of comprehensive applications for disabled children and their families (Bernheimer et al., 1990).

Ecocultural theory is one of these new approaches that integrates family ecology, members and culture into one ground (Worthman, 2010). It enlarged and detailed the family systems and socio-ecological theories in several ways. For example, it included the family-constructed meaning of the families' circumstances (e.g. the goals and values influencing family perception of child disability), and also their responses to these circumstances. Besides, ecocultural theory is differentiated due to its applicability to families in all cultures, as the theory is based on cross-cultural literature (Bernheimer et al., 1990).

Additionally, ecocultural theory explains ecocultural dynamics for disabled children and their families. As a result, the current study is based on ecocultural perspective owing to its affluent structure and approach to disability.

\subsubsection{Ecocultural Theory}

The term ecocultural or ecological/cultural refers to the physical and social characteristics of the family context (Bernheimer et al., 1990). Thus, the theory assumes that culture is a broader context that includes tasks, people, goals, believes, values, motives and traditions. These factors constitute the cultural pathway of people (Weisner, 1997; 1998; 2002a). These cultural pathways shape people's or families' life, activities, parenting practices, relationships and etc.

Furthermore, in ecocultural theory, family is defined as a context, shaped by embedded culture's beliefs, aims and activities. Each family forms their daily activities, routines and resources. These resources are available and fairly distributed with respect to needs 
of members within the family (Weisner, 1998). The main purpose of development is to achieve well-being according to ecocultural perspective (Weisner, 1997) because these activities, routines and resources help the child to internalize culture's values and beliefs in order to maintain well-being, that in turn increase the child's ability to learn adaptation and participation to life (Weisner, 2002b).

In sum, according to Weisner (1997), each culture constructs their ecology and this ecology influences the families' child rearing values and child development. To exemplify, in Abaluyia families, in Africa, parenting was explained in terms of intergenerational transferring of values and family-adaptive tasks such as obedience, respect, social interdependence, economic survival rather than the dyadic interaction and stimulation with their children (Weisner, 1997). In other words, they are more concerned with the child's survival and family adaptation instead of early stimulation for literacy or cognitive skills, and autonomy outside the home as in Western cultures (Weisner, 2002b). As a result, this perspective can explain the accurate, reliable and reasonable relationships between family characteristics and child development with the cultural characteristics they are embedded in (Phenice et al., 2009).

\subsubsection{Culture, Family and Disability in Ecocultural Theory}

Ecocultural theory emphasizes that developmentally delayed or disabled children should be examined within the range of the familial and cultural characteristics because they cannot be separated from their families, cultural values, beliefs, ecological resources and restrictions. So, ecocultural theory takes explanatory model as its basis, instead of medical and social models in which disabled individuals are seen passive, and disability is seen as only medical or social issue.

In explanatory model, the meaning of intellectual disabilities in a culture is constituted by cultural values, beliefs, meanings and tools in which individuals were embedded (Daley \& Weisner, 2003; Skinner \& Weisner, 2007). Therefore, explanatory model provides an extensive perspective for researchers on individuals' and families' understandings and experiences related to disability within social contexts of family, 
school, services, and peers (Skinner \& Weisner, 2007). Besides, although, this theory takes the perspectives of professionals in this field into consideration especially for disabled children, it emphasizes family' perspectives more. Professionals in this field should analyze the risks (necessities) and opportunities (supports) of the family, how family interpret and perceive these factors (Bernheimer et al., 1990).

In an example, it was found that mothers of disabled children considering to send their children to a regular preschool seemed to be more focused on independent self-care and appropriate social skills (Kellegrew, 2000). However, mothers who had decided to send their children to a special education showed greater interest in their child's academic daily activities. Also, one of these mothers who decided about special education claimed that since the child would learn self-care skills in special education center, she didn't have to worry about it. As a whole, the professional in this field should assess the mother's goals, values, and beliefs in child rearing because it seems that they will shape the family ecological sources, in turn influencing child development. These are dynamic processes that interact with each other rather than passive processes seen in other models. It is speculated that professionals in this field could design an integrative family intervention that will capture both the needs of the family and the disabled child.

Ecocultural theory also captures many disabilities and discusses the effects of familial and cultural characteristics on the developmental outcomes of disabled children. Learning disability is one of them. Although, ecocultural theory assumes that learning disability is a neurobiologically originated problem, it also stresses that these children's development was influenced by the cultural characteristics such as values, goals and beliefs (Keogh et al., 1997). For example, ecocultural perspective argues the diagnosis criteria of learning disability. Literacy and academic achievement are the main goals of the families for their children in western countries. On the other hand, in agricultural societies, criteria of intelligence or competence of a child is whether s/he is doing a task independently or/and being appropriately according to his/her developmental age group (Keogh et al., 1997). Therefore, diagnosis criteria for learning disability could change due to ecology, resources, services, child care tasks, the nature of their early experience 
of literacy and learning process, the values, and goals of the family and culture. For this reason, children should be assesed by the criteria of the culture that child live in.

In conclusion, ecocultural theory examines how family and disabled child's development are affected from culture's beliefs, values and resources. Thus, ecocultural theory provides us a theoretical view in studying what is defined as learning disability, how the family perceive and interpret learning disability, deal with it and how the child development is affected.

\subsection{THE FACTORS RELATED TO DISABLED CHILDREN IN ECOCULTURAL THEORY}

Impairment is not the product of individual pathology. Thus, the collective activism of people with 'learning difficulties' are incorporated into social theorizing in order to understand and recognize the social and cultural formations of the inability (Goodley, 2001). In the ecocultural theory, family's social support resources and child developmental outcomes were mainly assessed factors in disabilities. However, although the relationship between cultural values and child development were emphasized and analyzed for normally developed children, all these factors were not studied specifically for learning disabled children. Therefore, in the following section, these factors were summarized both within the scope of ecocultural theory and with findings of learning disability literature.

\subsubsection{Family's Social Support Resources and Disability}

Ecocultural theory has underlined the vitality of examining economic factors, child security, health and education, family support resources, sociocultural factors, domestic and child workload in developmentally delayed children's families (Nihira et al., 1994). In studies of children with developmental delays or disabilities 12 ecocultural factors were assessed (Keogh \& Weisner, 1993; Nihira et al., 1994; Skinner \& Weisner, 2007). Fifth of these factors (integration into non-disabled networks, multiple services use and availability, integration into disabled networks, family workload related to disabled 
child, and instrumental help for family) predicted 30-60\% variance of the child development, communication and daily living skills such as child socialization skills (Nihira et al., 1994). Also, family cohesion and marital satisfaction, socioeconomic status and instrumental support significantly predicted child outcomes.

These ecocultural support factors were thought to be helpful for families to adapt to the disability, shape family activities and parenting practices. Also, family support resources are accepted to provide a protective context for the family and disabled children (Morrison \& Cosden, 1997). Then, shaped activities and practices would predict the child developmental outcomes. In an example, support factors may diminish stress of caregivers along with leading to effective care (Sandy, Kgole, \& Mavundla, 2013). This was the main assumption of ecocultural theory.

The family support resources were found be significant factors in predicting children development in developmental delayed children. However, the current study aimed to analyze the relation between the ecocultural support resources and child outcomes in learning disabled children. Although it was defined 12 ecocultural characteristics in evaluating children with disabilities, 7 of them were included in the present study:

1. Socioeconomic status was described as income, parent's occupation or employment status,

2. Multiple service usage was described as accessibility and utilization of services for disabled child,

3. Supplemental help for family was described as additional help to family in caring child related activities such as relatives or grandparents,

4. Help available within family was described as availability of help to caring of disabled child within the family such as husband or sibling,

5. Connectedness of family was described as the quality of relationship between parents and father participation and help in disabled child care,

6. Variety and amount of formal and instrumental help was described as usage of variety of supports form professionals, programs or partner, 
7. Use of information from professionals was described as parents' effort of information-seeking for child prognosis and well-being (Nihira et al., 1994).

In the current study, families social support resources were assessed in five dimensions. The variety and amount of formal and instrumental help, use of information from professionals and multiple service usage were comprised as informational support. Informational support was assumed to be a significant support in adaptation to learning disability and helpful for families (Greenspan, 2004). However, the studies including the relationship between perceived informational support and child problem behaviors were limited in learning disabled children.

Second, help available within family and supplemental help for family was included under perceived caregiving support. In the current study, caregiving support also included both within and out of the family help in child care. This support was also found to be crucial for learning disabled children's mothers (Greenspan, 2004; Waggoner \& Wilgosh, 1990). It explained that help from father or other close relatives support mothers to engage in outside activities such as having more time for their work related activities, in turn decreasing their sense of isolation (Sandy et al., 2013).

Third, connectedness of family as described in ecocultural factors (Nihira et al., 1994), was assessed as intimate relations support in the study. Intimate relations support includes the quality of the partner support in the family. It was stressed that a cohesive and supportive family relationship could be a protective factor for learning disabled children development (Morrison \& Cosden, 1997).

Forth, socioeconomic status was assessed as income level and parent's occupation or employment status in Nihira et al. (1994). Income level was assessed in sociodemographical variables. However, instead of assessing only income level, it was aimed to assess financial support as a support resource of the family, how the family perceive this support and how it influences child development. 
Last, emotional support was also assessed. In ecocultural support resources, the additional help was accepted as significant factor. However, the emotional dimension of the help was missing. As a result, in addition to caregiving support and intimate relation support, emotional support was also added. This support captures the availability and satisfaction of emotional support (e.g. sharing one's anxiety, feelings, happiness with someone) taken from close relatives, friends and etc.

Finally, all the seven factors mentioned above were covered with these four support resources (perceived informational, caregiving, intimate relationships and financial support), and emotional support was added. The effect of these five dimensions of perceived support on child outcome was assessed in the present study with ecocultural perspective as our back drop.

\subsubsection{Outcome Variables}

In studies children conducted with developmental delays or disabilities within the perspective of ecocultural theory, child development status, communication and daily living skills, and adaptive behaviors were mainly studied (Keogh \& Weisner, 1993; Nihira et al., 1994; Skinner \& Weisner, 2007). In the current study as well, child problem behaviors were taken as the outcome variable. In the next part, the child problem behaviors were mentioned.

\subsubsection{Learning Disabled Children and Problem Behaviors}

Child adjustment is defined as adaptation to particular contexts (e.g. school environment) and related experiences (Damon \& Learner, 2008). It includes both positive behaviors such as hope and effort and adaptive difficulties, such as problem behaviors. However, in the learning disability literature, internalizing and externalizing problems are mostly studied problems (Al-Yagon \& Mikulincer, 2004; Batum, 2007; Michaels \& Lewandowski, 1990). 
For learning disabled children, generally academic difficulties constitute the main problem, resulting in psychosocial maladjustment problems and they mainly co-occur (Greenham, 1999; Nelson \& Harwood, 2011; Undheim, 2003; Undheim, Wichstrøm, \& Sund, 2011). Also, low academic achievement, lack of social abilities, difficulties in communications and being rejected by peers were seen to lead to problem behaviors in learning disabled children (Korkmazlar, 1993, as cited in Batum, 2007).

In many studies comparing learning disabled children with normally developing children, statistics demonstrated that although both groups had problem behaviors, they were much higher in learning disabled group (Al-Yagon \& Mikulincer, 2004; Batum, 2007; Heiervang, Stevenson, Lund, \& Hugdahl, 2001; Nelson \& Harwood, 2011). Although problem behavior seems to be a more prominently studied outcome in learning disability literature, there appears to be a lack of research integrating the effects of both cultural (values) and familial (specific support resources) factors on problem behaviors. As a result, in this study, it was aimed to evaluate what contextual factors predict these outcomes in learning disabled children.

\subsection{Internalizing Problems and Externalizing Problems in Learning Disability}

Internalizing problems includes depression, anxiety, hopelessness, low feelings of selfworth and perceived competence, while externalizing problems are composed of aggressive-disruptive, delinquent, antisocial, hyperactive, inattentive behaviors, substance use and abuse (Greenham, 1999; Damon \& Learner, 2008; Richards, Symons, Greene, \& Szuszkiewicz, 1995; Undheim, et al., 2011). Based on literature, approximately one third of learning disabled children were found to be at greater risk in developing both problem behaviors as indicated in cross-sectional, longitudinal and meta-analysis studies (Dyson, 2003; Greenham, 1999; Michaels \& Lewandowski, 1990;

Nelson \& Harwood, 2011; Prior, Smart, Sanson, \& Oberklaid, 1999; Undheim, 2003).

Internalizing problems were seen to be higher for learning disabled children than for non-learning disabled controls (Greenham, 1999). Although internalizing problems are not easily detected as externalizing problems, learning disabled children reported more 
internalizing problems than externalizing problems (Nelson \& Harwood, 2011). The underlying reason of internalizing problems in learning disabled children attributed to ratings of low global self-concept and self-esteem. Also, the meta-analysis findings revealed that learning disabled children tended to attribute the failure or inefficacy to internal factors, such as lack of ability (Kavale \& Forness, 1996). Therefore, it might lead to feelings of helplessness in these children.

On the contrary, externalizing problems seems to be in sub-clinical level in these children (Greenham, 1999). According to one meta-analysis, the reason is thought to be that teachers seeing hyperactive behaviors as more problematic than internalizing problems for almost $80 \%$ of learning disabled students (Kavale \& Forness, 1996). Also, another meta-analysis indicated that there was a considerable overlap between diagnoses of learning disability and attention-deficit hyperactivity disorder, and they were usually comorbid in these children (Greenham, 1999). As a result, attention-deficit hyperactivity disorder thought to be a prominent factor that exacerbate the externalizing problems in these children.

Furthermore, when gender differences were analyzed, although some studies show that internalizing problems are seen more in girls (Prior et al., 1999) and externalizing problems more in boys (Michaels \& Lewandowski, 1990), a recent meta-analysis study demonstrated gender and grade level did not significantly moderate problem behaviors of children with learning disability (Nelson \& Harwood, 2011).

The studies conducted in Turkey also indicated that learning disabled children demonstrated both internalizing and externalizing problems (Korkmazlar, 1993, as cited in Batum, 2007), but higher internalizing problems than externalizing problems (Batum \& Öktem, 2011). On the other hand, when attentional problems were comorbid with the learning difficulty, children show more externalizing problems compared to children diagnosed with only learning disability (Batum \& Öktem, 2011). There were no differences for internalizing problems found between girls and boys, however learning disabled girls demonstrated more externalizing problems than boys when there is no comorbidity with attentional problems (Batum \& Öktem, 2011). They found more 
parental rejection in learning disabled girls than boys. So, it was explained that being rejected by mothers leaded to more externalizing problems in girls. Also, the reason of more parental rejection seen in girls was explained with the given value to children in Turkey as, more value given to boys than girls due to seeing boys as old age security.

Besides, these problem behaviors mainly and adversely affect the performance of children on cognitive and academic tasks by disrupting attentional focus, consuming space in working memory and resulting in inefficient information processing (Nelson \& Harwood, 2011). Also, families of learning disabled children with problem behaviors needed to show more effort in order to adapt to the situation (Michaels \& Lewandowski, 1990). Hence, these parents have higher levels of parental distress (Bonifacci et al., 2015).

In sum, both internalizing and externalizing behavioral problems appear to be more prevalent in learning disabled children than normally developing children control groups. Also, it was accepted that learning disabled children has more internalizing problems, and externalizing problems generally seemed to be comorbid with attention difficulties and hyperactivity in this children.

Overall, it is vital to recognize that learning disability on its own is not sufficient to explain problem behaviors. Consistent with this premise, it is planned to investigate familial factors (e.g. specific support resources) and cultural factors (e.g. values) in order to understand problem behaviors in learning disabled children.

\subsubsection{The Relationship between Perceived Social Support Resources and Child Problem Behaviors}

Generally, family support was seen to be lowest in families with learning disabled children compared to control group (normally developing children), but family support and cohesion was seen to be vital for both parents' well-being (Hassall, Rose, \& McDonald, 2005) and for children development (Heiman \& Berger, 2008). 
To begin with, informational support was found to be critical, and help from a professional increase child well-being and adjustment (Greenspan \& Winder, 2004; Rothman \& Cosden, 1995). Because of the fact that, receiving informational support would help parents to collect information about different intervention strategies for their child (Heiman \& Berger, 2008). In turn, they could better deal with child emotions and behaviors related with disability.

For financial support, it was argued that ecological factors such as poverty seems to be a crucial factor in learning disability level. To illustrate, poverty was likely to exacerbate the effect of disability on child development (Wagner \& Blackorby, 1996). With poverty due to economic forces, the disabled child has less chance to attain services such as taking additional educational help or to meet the daily economic needs (Brookins, 1993; Sandy et al., 2013). So, this negatively influence children's development.

With regard to intimate relations, emotional and caregiving support, mothers reported that caring for learning disabled was difficult and frustrating. Therefore, they needed emotional and practical (care) support (Sandy et al., 2013). For example, a cohesive and supportive family structure was thought to have an alleviating effect on the severity of the learning disabled children's academic difficulties and problem behaviors (Morrison \& Cosden, 1997). Also, marital adjustment, spousal support, and father support in child care were found to be insufficient, but crucial in developmentally disabled children's families (Bristol, Gallagher, \& Schopler, 1988).

In addition, studies generally include support as total score instead of a specific support resource. As a whole, when families with learning disabled children received low social support, their children reported poorer adjustment (Wenz-Gross \& Siperstein, 1998). On the contrary, Pearson and Chan (1993) indicated that there was no significant influence of social support for the learning disabled children's parents. However, they claimed that studies need to differentiate between received and perceived support. This point may change the effect of support on families and children. For this reason, both 
availability of the specific support and satisfaction from the specific support were included in the current study.

Furthermore, in Turkey, studies conducted about social support mainly include the importance of social support, the relation between perceived social support and the mother's, child's or family's well-being or stress. To illustrate, the main problem of disabled children's families was argued to be lack of social support (Özsoy et al., 2006). Nevertheless, if there was high level of social support, low level of hopelessness (Karadağ, 2009), better level of coping with stress (Atalay, 2013) were observed in these families. Besides, Kaner (2004) also found that lack of family support resources predicted high parent's stress level. These were positive outcomes of support on family. In addition, for the child, perceived high social support in the family predicted positive self-development (Akınc1, 2011). It was seen that the studies conducted in Turkey about disability mainly overlooked the differential effects of specific support resources on child problem behaviors. Thus, differently from previous studies, the effects of specific support resources were investigated separately as indicated in ecocultural theory.

In conclusion, based on the literature, although there were limited studies on the relation between specific social support resources and child problem behaviors, it seems that support has a positive influence both on family and child.

\subsubsection{Values}

In ecocultural theory, it was assumed that the actions of people (Bernheimer et al., 1990) such as parenting practices and families' daily activities, are influenced by both cultural and individual values, and values are the product of the culture (Weisner, 1998; 2002a; 2009). According to Schwartz (1999) "cultural values represents the implicitly and explicitly shared abstract ideas about what is good, right and desirable in a society". Thus, values are seen as the conception of guiding that people's desirable actions, explaining and determining people and their actions (Schwartz, 1999). There are three main needs that values capture. Values; (1) are needs of biological organism, (2) essential part of social interaction coordination, (3) necessity of wellbeing and 
continuity of generations. Also, values can be sorted by importance and can trade-off between themselves (Schwartz, 2006).

In Schwartz (1999) values theory, 10 basic needs were defined. They have dynamic, both similar and contrast relation between each other, and they constitute a circular model (Schwartz, 2006; Schwartz \& Bardi, 2001; Schwartz \& Boehnke, 2004). Values are situated in 4 pole on the circular model. More broadly, according to studies, values in the first pole that is related to individualistic values are defined as "openness to change" and values in the opposite pole that is associated with collectivistic values are defined as "conservation" (Demirutku, 2007; Schwartz, 1990;) and these two poles were used in the current study.

Openness to change pole includes "stimulation and self-direction" values (Demirutku \& Sümer, 2010; Schwartz \& Bardi, 2001). Stimulation is defined as seeking excitement, challenge, and novelty, whereas self-direction value is described as giving importance to independency, creating and exploring new things in the life (Schwartz et al., 2001). It was emphasized that values like self- help promotes better coping with problems which, in turn, might promote positive well-being. More, Schwartz and Bilsky (1987) categorized self-direction, and stimulation as representing primarily growth needs that correlate positively with subjective well-being.

Furthermore, "security, conformity and tradition" values are in the conservation pole (Schwartz \& Boehnke, 2004). Security is defined as need of safety, harmony and stability of life. Besides, conformity includes limitation of one's desirable actions in giving no harm or distress to others (Demirutku \& Sümer, 2010), and tradition is described as dedication of customs and ideas of culture and religion (Schwartz et al., 2001).

Contrary to values of the conformity, tradition, security; openness to change values are often considered as more related with growth and low anxiety (Schwartz et al., 2012). However, Sagiv and Schwartz (2000) stressed the relation of values to well-being requires taking into account value congruity with the environment. 


\subsubsection{Parenting and Values}

Link of the values with different cultural interest's canalized the researchers to study relation of values with family or parenting practices and its relation with child outcomes. For instance, societies differ according to the given importance to the role of formal education. As a result, this would affect the function of parent-child relations differently than the given importance to the role of informal education (Trommsdorff \& Kornadt, 2003), and these relations would also influence child development (Weisner, 2002a; 2002b).

In studying parenting practices differences and culture, the dimension of individualismcollectivism have been used to determine the tendency of societies or/and individuals. Collectivism was defined as giving priority to relatedness, conservation, loyalty and interdependence between generations, and mainly seen in rural and traditional societies especially eastern countries (Kağıtçıbaşı, 2009). However, individualism was described as giving priority to autonomy, openness to change, and independence between generations, and mainly seen in urban life especially in western countries (Kağıtçıbaşı, 2009). Therefore, the following literature after this point was conceptualized with concepts of individualistic and collectivistic values instead of other descriptions.

To begin with, in collectivistic cultures, children are mostly perceived as the main source of old age security and financial assistance (Kağıtçıbaşı, 1996; 2009). Child is dependent on parent, and parents prefer to use more parental control (Demirutku, 2007; Rudy \& Grusec, 2001). In these cultures, authoritarian parenting was the mostly observed parenting style. Since there is valuing of obedience and respect for authority with an absolute set of standards, parents do not encourage the child's feelings of autonomy (Baumrind, 1971). Therefore, authoritarian parenting was argued to be destructive to socialization and development of the child.

Next, in individualistic cultures in which authoritative parenting is mostly seen, there is less control in child rearing, and both intergenerational and interpersonal independence was found (Tudge et al., 2000). Authoritative parenting facilitates child outcomes due to 
including firm control, encouraging autonomy, and willingness to reason and negotiate in a more effective familial environment (Garcia \& Gracia, 2009). Also, authoritative parent's children were seen to be more understanding, social and extravert (Weisner, 2009).

On the contrary, while some studies comparing the cultures as individualistic and collectivistic (Schwartz, 1990; Triandis, 1993), some researchers argue that both values could coexist in some cultures and/or individuals (Green, Deschamps, \& Paez, 2005; Kağıtçıbaşı, 1996; 2009; Tamis-LeMonda et al., 2008). In these societies/individuals, there is a combination or coexistence of individual and group/family loyalties, because both values are accepted as basic needs of individuals (Kağıtçıbaşı, 1996; 2009). A pertinent example shows that even though collectivism predicted parental control (authoritarian parenting) among Egyptians, it did not predict lack of warmth and negative outcomes, indicating the presence of coexistence of values (Rudy \& Grusec, 2001). Also, Imamoğlu's (1987) findings demonstrated that although parents in Turkey started to emphasize less obedience and loyalties, they still wanted their off springs to maintain close ties (as cited in Kağıtçıbaşı, 2009). These findings demonstrated that rather than individualism or collectivism (separation or dependence), they are two basic needs of human and could coexist in societies, such as in Turkey.

All these literature was based on normally developing children and their families. Although there were very limited amount of studies in learning disabilities, it was found that especially mothers of learning disabled children were high on conformity values (Miletic, 1986), and were more rigid (Heiman \& Berger, 2008). Also, in collectivistic cultures, failure of the child was seen as the result of unsuccessful parent-child relationship instead of child's own duty (Tews \& Merali, 2008). In order to improve the academic performance of children, parents may become stricter because they believed that that increasing discipline would lead to better child outcomes and successful parent child relationship in learning disabled families. On the contrary, it was seen that mothers who internalized individualistic values is believing more in the importance of early development in infancy instead of cultural beliefs that is mostly seen in traditional cultures (Harry, 2002). 
According to Weisner (2002a), all these findings demonstrate that it was not accurate to generalize social differences because there were differences in parenting practices both within culture and between cultures. To illustrate, child rearing values, parent-child relations and development are effected by broader contextual variables such as the family, the neighborhood, the socioeconomic system and values as stressed in ecocultural approaches. However, the effects of parents' values, such as collectivistic and individualistic values, on learning disabled children problem behaviors are seen to be not studied in detail to this date.

In conclusion, in this present study, Weisner's ecocultural theory was assessed using Schwartz's values for evaluating disabled children's problem behaviors. Although values were accepted one of the significant cultural variables that effect child development in ecocultural theory, it was not assessed how these values influence learning disabled children. As a result, values (openness to change and conservation) included in the current study as cultural variables to see the differential effects of mothers' values on learning disabled children problem behaviors.

\subsubsection{The Relationship between Values and Perceived Social Support}

In ecocultural theory, values are assumed to influence the family activities, resources and routines of the family (Weisner, 2002b). The literature was mainly based on how values shape the individuals' tendency or chance to get the support.

Studies on individual differences stressed that individual's values could be a significant factor in seeking support from others (Goodwin, Costa, \& Adonu, 2004). Also, how an individual perceive the support may be more likely to be related to individual values. To illustrate, Triandis, Leung, Villareal, and Clack (1985) argued that individualism was related with lower social network and lack of resources whereas collectivism was associated with a better quality of social support from the others.

On the contrary, both Goodwin, Costa and Adonu (2004), and Feather, Woodyatt and McKee (2012) findings demonstrated a different pattern. Goodwin et al. (2004) found 
that individuals low on collectivistic values reported greater perceived support. Similarly, Feather et al. (2012) found that collectivistic values such as security were negatively related to social support. So, in both studies, support was negatively related with collectivistic values.

These findings could be explained in two ways. First, individualistic values support assertive and sociable interactions, and also predicted a perception of a healthy support network (Goodwin et al., 2004). Another reason could be that although collectivistically oriented individuals are socially focused, they focus more on the narrow in-group members than strangers (Schwartz, 1990). However, individualistically oriented people focused more on welfare of universe or out-groups, hence looking for larger social networks (Schwartz et al., 2012). Also, implicit support (receiving support from narrow environment, but does not involve the self-disclosure of personal problems) is regarded as culturally appropriate in most collectivist contexts, whereas explicit support (disclosing and distressing thoughts or emotions and relying on close others for advice) is considered culturally congruent in individualistic contexts (Chang, 2015).

For disabled children, how values shape the support resources of the family was not studied before to authors' knowledge. Studies reviewed that there was greater familial and religious support within the ethnic minority families (Harry, 2002). Also, mothers of learning disabled were found to be scored higher on both support and conformity scales (Miletic, 1986). So, it was thought that emotionally dependent mothers may be more close to their social environment. Also, for fathers who were high in independence were concluded to be low in receiving social support. Nevertheless, it was also argued that feeling shame about children's learning problems might restrain families in a collectivistic culture from looking for external help in order to keep problems within the family (Tews \& Merali, 2008).

In conclusion, although the relationship between individual-cultural levels and support is a current debate in cross cultural literature, the individuals and/or also families' values may play a key factor on how they perceive the social support resources. As far as it is known, there are very limited studies that discuss the relationship between social 
support and values in learning disabled children. Thus, such research could shed light on how to bridge the gap between values and perception of resources within the culture.

\subsubsection{The Relationship between Values and Child Problem Behaviors}

While individualistic values were positively related with education level of adults, collectivistic values were positively associated with religious belief (Schwartz et al., 2001). Besides, in family related studies, it was argued that individualistic values mainly positively correlated with parental acceptance and warmth, whereas collectivistic values were mainly related with parental control (Demirutku, 2007; Rohan \& Zanna, 1996). However, according to Kağıtçıbaşı (2009), in some sociocultural context, parental control was common and children perceive it as normal. It was found that authoritarian parenting resulted in negative developmental outcomes mainly in individualistic cultures (Rudy \& Grusec, 2001; 2006).

Although there is no direct result demonstrating a relation between parenting practices in disability and individualistic/collectivistic values in previous studies, there are some studies that emphasize the relation between parenting and child outcomes. As mentioned before, mothers who internalized collectivistic values believe that using more harsh discipline methods was related with better child outcomes. However, it was argued that families that have has ability in adapting to changes were likely to deal with disability more successfully, and they were found to be supportive in care of learning disabled child (Morisson \& Cosden, 1997). In other words, it was explained that families with rigid boundaries have difficulties in adapting to disability.

In sum, even though there are few research in disability, values can be a significant factor in disabled children's families. Thus, assessing parents' values could help to developmental psychologists to understand how cultural variability influence families in dealing with the disability, the families' resources, and developmental outcomes of the children (Bemheimer et al., 1990). Briefly, it was found that while control and strictness which were related with conservation can be destructive for families and for children, ability in adapting to changes and parental warm which were related with individualism 
can be favorable for children. Also, there are controversial findings for values and support. However, it was also argued that instead of separation of values, internalizing both values was possible for some cultures (e.g. Turkey), and leads to balance of parental control and warm in parenting, in turn positively influencing the child. As a result, for current country, it was expected that parents who were internalized both values would have more perceiving social support resources, and their learning disabled children would demonstrate lower problem behaviors.

\subsubsection{The Relationship between Learning Disability Level and Child Problem Behaviors}

Learning disability is a general category of difficulties in any of specific areas such as reading, writing, mathematic, and expressive language. When children has more than one difficulty in these specific domains, the child learning disability level becomes more severe. Furthermore, when attention deficit disorder and/or hyperactivity is comorbid with learning disabilities, it was seen that reading deficits were typically intensified, became more severe, and more resistant to interventions (Rothman \& Cosden, 1995), and more externalizing problems was seen in these children (Greenham, 1999).

Thus, it seems that there was difference between child learning disability severity and child outcomes. Also, children with severe learning disabilities were more prone to show a number of social and behavioral deficits. Given that, when the child had difficulties in more than one area (e.g. both reading and writing or both reading and mathematics), the improvement became more difficult than children with mild or moderate deficits, especially in basic reading skills (Lyon, 1996). Also, Bruck (1986) investigated that children with more severe manifestations of learning disability were likely to manifest both an increased number and increased severity of social skills deficits.

In conclusion, different from previous study that had been done within the ecocultural perspective (e.g. Nihira et al., 1994), in the current study, child disability level was not 
studied as an outcome variable. There are two reasons of that. First, disability level was seemed to be a significant factor in influencing the child and the family (Rothman \& Cosden, 1995). Also, not analyzing the severity level (showing difficulty in more than one area) was emphasized as a limitation in studies when analyzing family functioning and social support of learning disabled families (Heiman \& Berger, 2008). As a result, within this study, different from the ecocultural theory, it was thought to analyze child learning disability level as a control variable instead of outcome variable in order to see whether child learning disability severity changed the relationships between variables.

\subsection{THE PRESENT STUDY}

Ecocultural theory has been stressing the assessment of cultural and familial factors in disabled children. In this regard, families social support resources and the effect of culture were argued to be significant factors for families and the child development. Although no studies were found that comprise all the factors to this date, the theories and models emphasize that values and family social support resources influence child's developmental outcomes (Weisner, 2002a).

In this study, the relations were examined in four main steps; (1) the relation between support resources and child problem behaviors, (2) the relation between support resources and child problem behaviors after controlling for disability level, (3) the effect of cultural values on perceived support resources after controlling child disability level, (4) the influence of values on child problem behaviors after controlling child disability level in order to see direct of the values on child problem behaviors.

As a result the following hypotheses were aimed to test within the current study:

Hypothesis 1: Mother's perceived support resources (caregiving support, emotional support, informational support, intimate relations support and financial support) would negatively predict both child internalizing and externalizing problems. 
Hypothesis 2: Mother's perceived support resources (caregiving support, emotional support, informational support, intimate relations support and financial support) would negatively predict both child internalizing and externalizing problems, after controlling the child learning disability level.

Hypothesis 3: Mothers who have high scores in both openness to change and conservation values' scales would positively predict mother's perceived support resources (caregiving support, emotional support, informational support, intimate relations support and financial support), after controlling the child learning disability level.

Hypothesis 4: Mothers who have high scores in both openness to change and conservation values' scales would negatively predict both child internalizing and externalizing problems, after controlling the child learning disability level. 


\section{CHAPTER II}

\section{METHOD}

\subsection{PARTICIPANTS}

The sample was composed of 128 mothers of learning disabled children attending special education centers and the children's teachers. However, after missing scales and outliers were excluded, 90 cases reported by both mothers and teachers were included in the study. There were 42 learning disabled girls and 48 learning disabled boys. The mean age of children was $9.31(S D=1.79)$. Children's mean age of taking the learning disability diagnosis was $7.93(S D=1.48)$, the mean of duration of children going to special education was 14.29 months $(S D=16.06)$. All children also continue to their formal education. The data was collected from different counties of Ankara. The data was collected using convenience sampling method. All 90 children had been only diagnosed with learning disability through previous psychoeducational evaluations conducted by Guidance and Research Center (RAM). Children with comorbid diagnosis were excluded from the sample.

Also, mothers who were married, and had only one biological disabled child were included in the study. The mean age of the mothers was $37.85(S D=7.30)$, and the mean of mothers' duration of marriage was 16.29 years $(S D=7.03)$. Also, $86.7 \%$ of the mothers were not employed $(N=78)$ while $13.3 \%$ of them were employed $(N=12)$. Mothers were mainly graduated from primary school $(N=49)$ and secondary school $(N$ =21). The education level of the mothers was presented in Figure 1. Besides, mothers' perceived income was assessed and the participants were mainly come from middle income group $(N=50)$ (see Figure 2). 


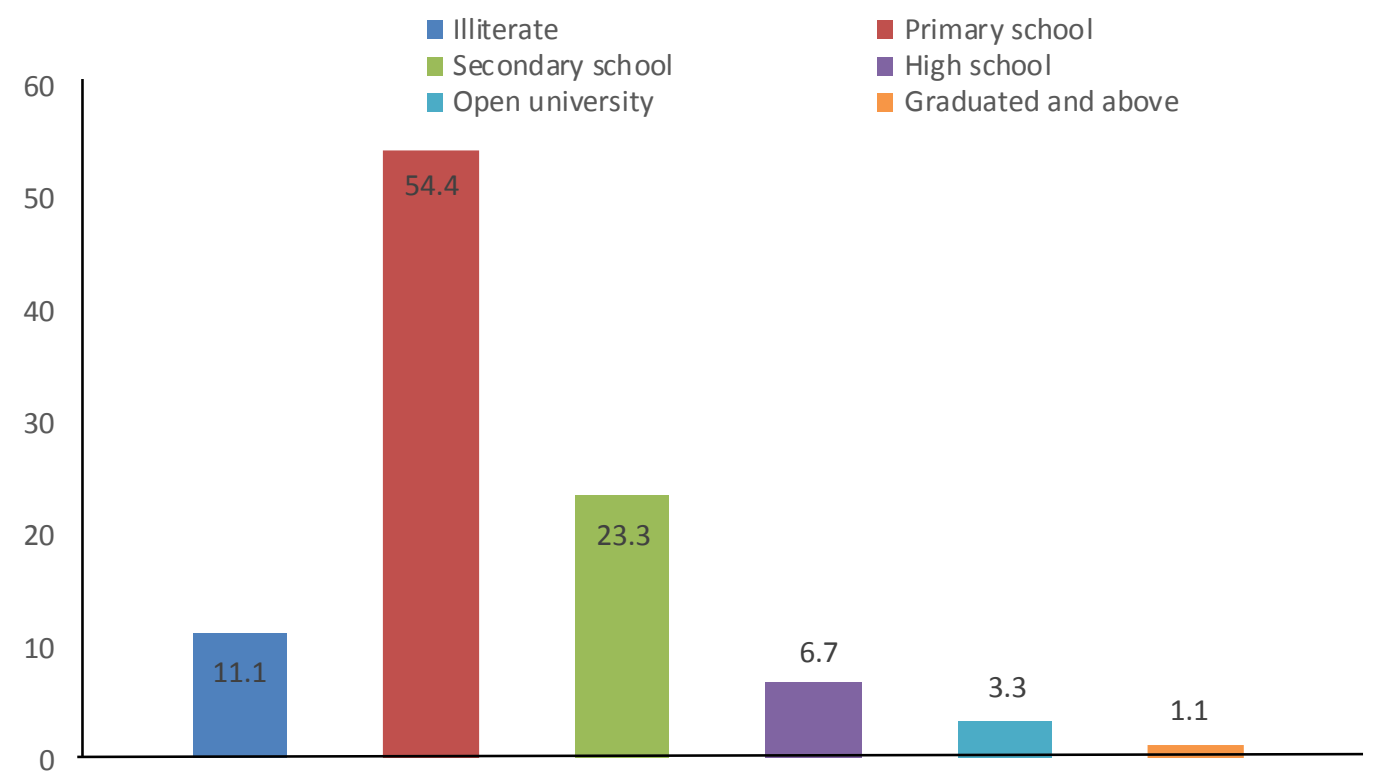

Figure 1. Percentage of Education Level of Mothers (\%)

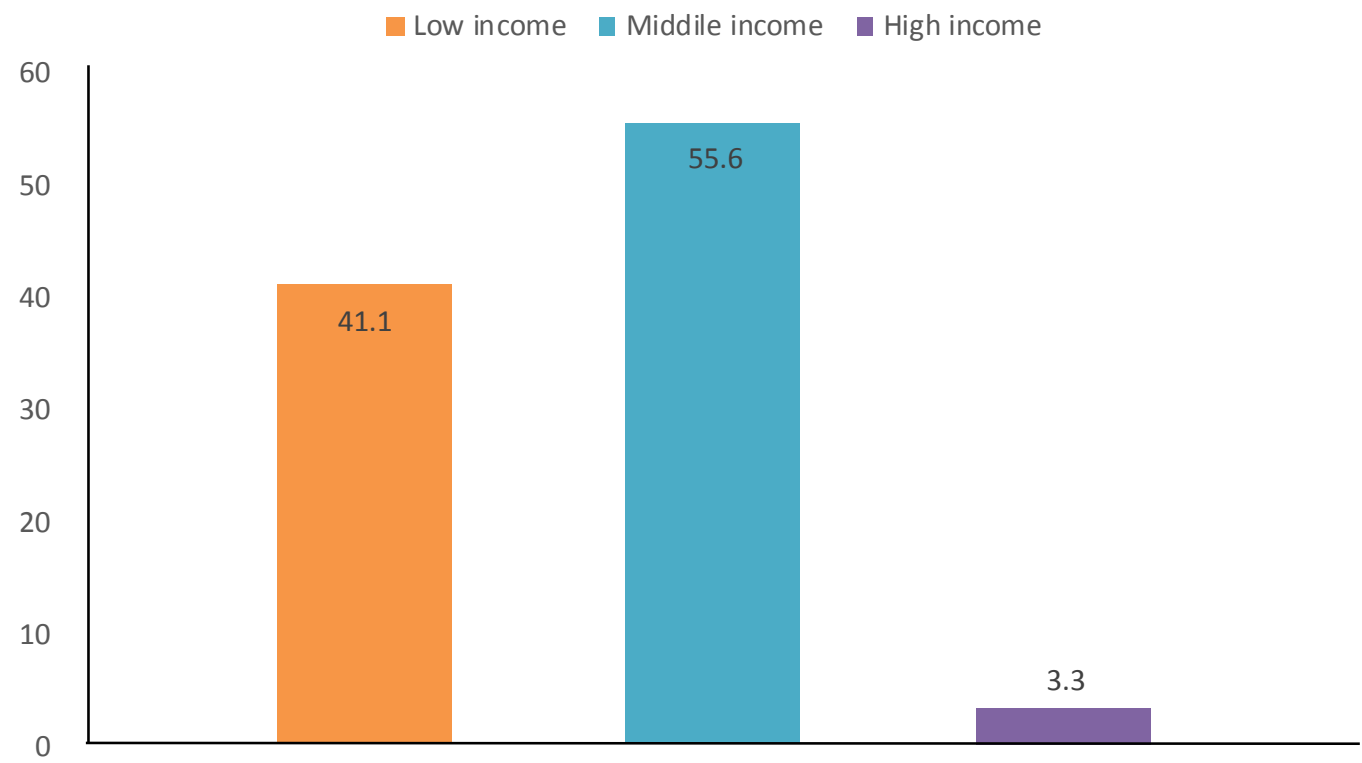

Figure 2. Percentage of Perceived Income Level of Mothers (\%) 


\subsection{MEASUREMENTS}

In the current study, Social-Demographic Information Form was used in order to determine participants' characteristics; Family Support Scale was used to examine mothers' perceived support resources and their satisfaction from them; Portrait Values Questionnaire $(P V Q)$ was used to determine mothers' values; Specific Learning Disability Symptom Check List (Teacher Form) was used to assess reading, writing, learning, attention, math abilities of learning disabled children. Last, Child Behavior Problem Scale (Teacher Form) was used to specify child problem behaviors. In the following part, the mentioned scales were summarized.

\subsubsection{Social-Demographic Information Form}

Mother's age, education level, number of children, working status, perceived family income, duration of marriage, diagnosis of the child, and child's age, gender, age of taking the diagnosis, duration of special education (in months), other diagnosis (to exclude the child if there any other diagnosis, e.g. attention problems) were included as the demographical questions in the form.

\subsubsection{Family Support Scale}

Family support scale was developed by Kaner (2003) to determine social support resources of parents with disabled children. The scale measures support resources of parents or caregivers of intellectually disabled, deaf and blind, psychically disabled children and children having speech disorders between ages 1-18. There are five dimensions of the scale: emotional support ( $\alpha=.91$, "Konuşmak ihtiyacı duyduğumda, beni gerçekten dinleyeceğine inandığım birileri var”), informational support ( $\alpha=.86$, “İhtiyacım olduğunda, öğretmen, danışman, yönetici gibi bana yardımcı olacak birileri var"), caregiving support ( $\alpha=.90$, "Çocuğumun bakımında bana yardımcı olacak birileri var"), intimate relations support ( $\alpha=.85$, “Uzun ve yorucu bir günün sonunda kendimi bitmiş, tükenmiş ya da sıkıntılı hissettiğimde, beni rahatlatacak birileri var”), and financial support ( $\alpha=.91$, "Param olmadığı zaman, çocuğumun bir ihtiyacını almak 
zorunda kalsam, bana borç para verecek birileri var"). Test-retest reliability coefficients are $.99, .97, .97, .97, .95$ and .99 , respectively.

Scale was composed of 31 items and parents choose one of the 4 options for each item ("4 always", "3 sometimes", "2 rarely" and "1 never") whether they have anybody that support them. The mothers can get an overall score ranged from 31 to 124. The Cronbach's alpha coefficients for the current study were found for emotional support, .92; informational support, .89; caregiving support, .84; intimate relations support, .87; financial support, .81; and total scale's alpha is .95 .

In the revised version of the scale, there is also a question that asks whether "they are satisfied with that specific support resource" (Kaner, 2010). The participants need to answer as "4 very satisfied", "3 satisfied", "2 a little satisfied" and "1 not satisfied". The mothers can get an overall score ranged from 31 to 124 . The high score means that parents have high family support resources. Last, Cronbach's alpha coefficients of satisfaction were found for emotional support, .93; informational support, .91; caregiving support, .85; intimate relations support, 88; and financial support, .84; and total scale's alpha is .96 in the current study.

In sum, there are two versions of the scale. Since financial support was an important factor in the ecocultural perspective, old version of the scale was used in the current study. Besides, satisfaction part was added to the old one in order to see the fit of perception and satisfaction. However, due to high correlation between both having support and satisfaction from support $(r=.92, p<.00)$, the aggregated scores of them was used in the analyses.

\subsubsection{Portrait Values Questionnaire (PVQ)}

Portrait Values Questionnaire (PVQ) was developed by Schwartz et al. (2001) in order to assess individual's values. This scale includes 40 short verbal portraits of hypothetical individuals, describing one's goals, or wishes that point implicitly the importance of the given value. The participants should rate the level to which the 
portrayed person on each item was similar to themselves on a 6-point scale ("6 - very much like me" to " 1 - not like me at all").

It includes 4 poles, but 2 poles were included in the current study. The values in the openness to change pole, stimulation ("He looks for adventures and likes to take risks. He wants to have an exciting life") and self-direction ("It is important to him to make his own decisions about what he does. He likes to be free to plan and to choose his activities for himself."); and the values in the conservation pole, security ("It is important to him to live in secure surroundings. He avoids anything that might endanger his safety"), tradition ("Religious belief is important to him. He tries hard to do what his religion requires") and conformity ("It is important to him always to behave properly. He wants to avoid doing anything people would say is wrong.") were used.

Demirutku (2004) adapted the scale to Turkish population and found that Cronbach's alpha coefficients were ranged between .63 (tradition) to .75 (conservation). Also, test retest reliability was ranged between .65 (self-direction) and .82 (tradition). In the current study the two poles were used as subscales and alpha coefficients were found as .53 for openness to change pole and .78 for conservation pole.

\subsubsection{Specific Learning Disability Symptom Check List (Teacher Form)}

The check list was developed by Erden (unpublished manuscript) to assess reading, writing, learning, attention, math abilities of the learning disabled children. It includes 78 items and 4 subscales as understanding and using verbal and nonverbal language (e.g. "Sözcük dağarcığı yaşıtlarına göre daha azdır ve sıklıkla doğru kelimeyi bulmakta zorlanır”), sustaining attention (e.g. “Okurken kapı veya zil çaldığında kaldığım yeri tekrar bulmakta zorlanır"), failing in reading and writing (e.g. "Okurken hata yapar. Metni doğru okuyamaz"), and coping with mathematical concepts (e.g. "İki ve daha fazla basamaklı sayıları doğru yazıp, okuyabilir”). Teachers completed this check list demonstrating the level of the frequency of the difficulties the child face in their abilities for each domain on 5-point scale ("5 - very extremely" to " 1 - not at all"). The Cronbach's alpha coefficients were found as .90 and higher for the subscales. For the 
current study, total score of the check list was included in the analysis, and Cronbach's alpha coefficients were found as .96 for total scale.

\subsubsection{Child Behavior Problem Scale (Teacher Form)}

The scale was developed by Kaner (2007) in order to detect problem behaviors of disabled children and the level of discomfort of the teacher related to the problem behavior. The scale includes 45 items and 4 subscales as conduct problems; immature and internalizing problems; hyperactivity and externalizing problems, and attention problems. The Cronbach's alpha coefficients were found .75 and above for the subscales. The teacher was asked to rate the student behaviors in the list (e.g. internalizing problem "İçe kapanıklık", externalizing problem "Yerinde duramama, aşırı hareketlilik") on 4-point scale ("3 - I feel extreme discomfort" to " 0 - The child don't perform the behavior").

In the current study, only immature and internalizing problems, and hyperactivity and externalizing problems subscales were used. The Cronbach's alpha coefficients were found .86 for immature and internalizing problems; .87 for hyperactivity and externalizing problems.

\subsection{PROCEDURE}

First, the ethical permission was taken from Hacettepe University Ethic Committee. Then, the data was collected in 2015-2016 fall semester. The children that continue to special education centers were selected and the participants were contacted by the help of three special education centers. The aim and goals of the study were discussed with mothers whose children continue to these special education centers via phone. Then, a meeting was arranged with mothers who were accepted to take part in the study. The families were interviewed by the researcher in their homes or in the special education center according to mothers' preferences. 
During home visits, first the informed consent was signed by mothers, and the questions about study (e.g. the aim, goals and confidentially issues) were answered if there were any. The mothers who graduated from primary school and above filled the questionnaires by themselves in a silent room. However, mothers who were illiterate $(N$ =12) filled the questionnaires with the help of the researcher. The mothers answered the socio-demographical form, family support scale and portrait values questionnaires. Also, counterbalancing was applied in the order of the scales. Each session took approximately 45 minutes to complete.

Besides, teacher forms with an informed consent were delivered to teachers through mothers. The criteria for teacher evaluations was to know the child at least for 3 months. The teacher forms were collected from the mothers in the second short visit.

\subsection{DATA ANALYSIS}

All data was analyzed in IBM SPSS23. In order to see relationships between families supports, values, child learning disability level and child problem behaviors; Pearson correlation analyses were conducted. Next, regression analyses were conducted for prediction of problem behaviors, and then in order to see slope of interaction, a moderation analysis was conducted that recently introduced by Hayes (2013). 


\section{CHAPTER III}

\section{RESULTS}

This chapter consists of three main parts: a) the descriptive statistics of study variables; b) preliminary analyses including bivariate correlations of demographical and study variables (perceived social support, values, child problem behaviors and learning disability level); c) hierarchical regression analyses to examine the effect of both perceived social support resources and values on child problem behaviors. The analyses were computed with SPSS23.

Before analyzing main hypotheses, the data were screened in terms of accuracy and missing values. A total of 35 cases which have more than $5 \%$ missing values for any scale were excluded. 3 cases were identified as outliers and excluded from the analyses. Lastly, multicollinearity assumption was also met due to no correlation between variables higher than .90 .

\subsection{DESCRIPTIVE ANALYSIS OF STUDY VARIABLES}

Descriptive results for mothers' reports (values and perceived social support resources) and teachers' reports (child's problem behaviors and learning disability) were summarized in the Table 1. In total, 90 cases were reported by mothers and teachers. 
Table 1

The Mean and Standard Deviation of Study Variables

\begin{tabular}{llll}
\hline Variables & $N$ & $M$ & $S D$ \\
\hline $\begin{array}{l}\text { Mother related variables (mother report) } \\
\quad \text { Values }\end{array}$ & & & \\
$\quad$ Conservation & 90 & 4.94 & 0.75 \\
$\quad$ Openness to Change & 90 & 4.27 & 0.66 \\
$\quad$ Perceived social support resources total & 90 & 2.78 & 0.74 \\
$\quad$ score & & & \\
$\quad$ Caregiving & 90 & 2.53 & 0.94 \\
$\quad$ Emotional & 90 & 3.16 & 0.83 \\
$\quad$ Intimate relations & 90 & 3.00 & 0.88 \\
$\quad$ Informational & 90 & 2.37 & 0.91 \\
$\quad$ Financial & 90 & 2.73 & 1.04 \\
Child related variables (teacher report) & & & \\
$\quad$ Child problem behaviors & 90 & 0.54 & 0.49 \\
$\quad$ Internalizing problems & 90 & 0.76 & 0.57 \\
$\quad$ Externalizing problems & 90 & 0.47 & 0.73 \\
$\quad$ Learning disability level (total) & 89 & 2.87 & 0.72 \\
$\quad$ Coping with mathematical concepts (F1) & 89 & 2.90 & 0.90 \\
$\quad$ Understanding, using verbal and & 89 & 2.92 & 0.81 \\
$\quad$ nonverbal language (F2) & & & \\
$\quad$ Sustaining attention (F3) & 88 & 2.65 & 0.90 \\
$\quad$ Failing in reading and writing (F4) & 88 & 3.05 & 0.66 \\
\hline
\end{tabular}

\subsection{PRELIMINARY ANALYSES}

Bivariate correlations were examined as they were given in Table 2. Before starting analysis, the ipsatisation method was used in order to correct individual differences in scale use. Each person's responses were centered by subtracting their rating of values from their own mean score in order to convert absolute scores into scores that indicate the relative importance of each value in the value system (Schwartz, 1992; 2013). Values have effects on cognition, emotion, and behavior through an arrangement among multiple values that are simultaneously relevant to action, so ipsatising is both desirable and preferable in analysis (Schwartz, 2013; Tetlock, 1986). Also, Fischer (2004) stresses the congruity of ipsatising value scores for the Schwartz value theory 
instruments. That's why, in the present study, it was chosen to conduct the analyses with ipsative scores. For this sake, the study variables were also centred on their means.

\subsubsection{Correlations between Demographical Variables and Study Variables}

To begin with, income level was positively correlated with perceived social support total score $(r=.30, p<.01)$, emotional $(r=.25, p<.01)$, intimate relations $(r=.32, p<$ $.01)$, caregiving $(r=.26, p<.01)$, financial $(r=.37, p<.01)$, but not correlated with informational $(r=.14, p>.05)$ support. Next, education level was positively correlated with perceived social support total score $(r=.26, p<.01)$, emotional $(r=.23, p<.05)$, intimate relations $(r=.20, p<.05)$, informational $(r=.18, p<.05)$, financial $(r=.29, p$ $<.01)$, but marginally correlated with caregiving $(r=.26, p<.01)$ support. Duration of special education (in months) $(r=-.34, p<.01)$, child age $(r=-.38, p<.01)$, and duration of marriage $(r=-.24, p<.05)$ were negatively correlated with child learning disability level. Besides, duration of marriage was negatively correlated with child internalizing problems $(r=-.25, p<.05)$, however, duration of special education (in months) was positively correlated with externalizing problems $(r=.20, p<.05)$ (see Table 2). So, increase in the duration of education and marriage resulted in decrease in the child learning disability level and internalizing problems.

Also, child gender, number of children and mother age were not correlated with any study variable, that's why they were excluded from the analyses.

\subsubsection{Correlations between Predictor Variables}

Bivariate correlations between perceived social support and both values demonstrated that perceived social support total score $(r=.01, \mathrm{p}>.05)$, emotional $(\mathrm{r}=-.03, \mathrm{p}>.05)$, intimate relations $(r=-.03, p>.05)$, informational $(r=.06, p>.05)$, caregiving $(r=.00$, $\mathrm{p}>.05)$, financial $(\mathrm{r}=-.09, \mathrm{p}>.05)$ support was not correlated with openness to change $(r=.01, p>.05)$. Similarly, perceived social support total score $(\mathrm{r}=.02, \mathrm{p}>.05)$, emotional $(\mathrm{r}=.05, \mathrm{p}>.05)$, intimate relations $(\mathrm{r}=.05, \mathrm{p}>.05)$, informational $(\mathrm{r}=-.02$, 
$\mathrm{p}>.05)$, caregiving $(\mathrm{r}=.00, \mathrm{p}>.05)$, financial $(\mathrm{r}=-.01, \mathrm{p}>.05)$, support were not correlated with conservation $(r=.02, p>.05)$.

With regard to learning disability level, total score was negatively correlated with mother perceived social support resources total score $(r=-.30, p<.01)$, emotional $(r=-$ $.21, p<.05)$, intimate relations $(r=-.30, p<.01)$, informational $(r=-.25, p<.05)$, caregiving $(r=-.23, p<.05)$ support, but not correlated with financial $(r=-.19, p>.05)$ support (see Table 2).

\subsubsection{Correlations between Predictor and Outcome Variables}

Unexpectedly, perceived total social support total score were not correlated with both internalizing $(r=-.08, p>.05)$ and externalizing $(r=-.15, p>.05)$ problems. However, different support resources were significantly correlated with the problem behaviors. While, informational support was negatively correlated with internalizing problems $(r=$ $-.23, p<.05)$; emotional support $(r=-.22, p<.05)$, caregiving $(r=-.22, p<.05)$, and financial social support $(r=-.19, p<.01)$ were negatively correlated with externalizing problems. Therefore, different sources of support seem to be differentially effective in child problem behaviors.

Furthermore, conservation value was not correlated with both internalizing $(r=-.02, p>$ $.05)$ and externalizing $(r=-.13, p>.05)$ problems. However, openness to change value was marginally correlated with only externalizing problems $(r=-.17, p<.10)$.

Finally, the child learning disability level total score was positively correlated with child internalizing problems $(r=.27, p<.01)$. However, the child learning disability level total score was not correlated with child externalizing problems $(\mathrm{r}=.13, \mathrm{p}>.05)$. 
Table 2

Bivariate Correlations between the Study Variables $(N=90)$

\begin{tabular}{|c|c|c|c|c|c|c|c|c|c|c|c|}
\hline Variables & 1 & 2 & 3 & 4 & 5 & 6 & 7 & 8 & 9 & 10 & 11 \\
\hline Duration of education $* * *$ & -.05 & -.05 & $-.34 * *$ & .09 & .05 & .13 & .14 & .02 & -.03 & -.07 & $.20 *$ \\
\hline Child diagnose age & .00 & -.13 & -.11 & .00 & -.10 & .02 & .02 & .13 & -.01 & .02 & -.01 \\
\hline Child age & -.04 & -.06 & $-.38 * *$ & .14 & .03 & $.19 *$ & .14 & $.10 *$ & .01 & -.01 & .09 \\
\hline Income level & -.14 & $-.18^{\dagger}$ & .00 & $.30 * *$ & $.25 * *$ & $.32 * *$ & .14 & $.26 * *$ & $.37 * *$ & .01 & -.10 \\
\hline Duration of marriage & -.08 & .01 & $-.24 *$ & .01 & -.02 & -.02 & .03 & .07 & -.07 & $-.25 *$ & .00 \\
\hline Mother education & .03 & -.10 & .05 & $.26 * *$ & $.23 *$ & $.20 *$ & $.18^{*}$ & $.18^{\dagger}$ & $.29 * *$ & .17 & .07 \\
\hline 1.Openness & - & $.45 * *$ & -.08 & .01 & -.02 & -.03 & .06 & .00 & -.09 & -.01 & $-.17^{\dagger}$ \\
\hline 2.Conservation & & - & -.11 & .02 & .05 & .05 & -.02 & .00 & -.01 & -.02 & -.13 \\
\hline 3.Learning disability (total) & & & - & $-.30 * *$ & $-.21 *$ & $-.30 * *$ & $-.25 *$ & $-.23 *$ & -.19 & $.27 * *$ & .13 \\
\hline 4.Perceived social support (total) & & & & - & $.83 * *$ & $.90 * *$ & $.80 * *$ & $.80 * *$ & $.82 * *$ & -.08 & -.15 \\
\hline 5.Emotional & & & & & - & $.78 * *$ & $.46^{* *}$ & $.50 * *$ & $.58 * *$ & .03 & $-.22 *$ \\
\hline 6.Intimate relations & & & & & & - & $.59 * *$ & $.66 * *$ & $.71 * *$ & .03 & -.09 \\
\hline 7.Informational & & & & & & & - & $.58 * *$ & $.59 * *$ & $-.23 *$ & .05 \\
\hline 8.Caregiving & & & & & & & & - & $.72 * *$ & -.09 & $-.22 *$ \\
\hline 9.Financial & & & & & & & & & - & -.04 & $-.19 * *$ \\
\hline 10.Internalizing & & & & & & & & & & - & $.25^{*}$ \\
\hline 11.Externalizing & & & & & & & & & & & - \\
\hline
\end{tabular}

Notes. ${ }^{\dagger} \mathrm{p}<.10 . * \mathrm{p}<.05 . * * \mathrm{p}<.01 . * * *$ Duration of special education was measured in months. 


\subsection{REGRESSION ANALYSES}

\subsubsection{Hierarchical Regression for Perceived Social Support Resources and Internalizing Problems}

3.3.1.1. Results for Internalizing Problems without Controlling for Learning Disability Level

According to ecocultural theory, each individual support resource is significantly and differently effective in predicting child outcomes (Nihira et al., 1994). In line with this theory, whether different support resources predict child problem behaviors were analyzed first. Hierarchical regression analyses were conducted for each support resource and internalizing problems separately $(\mathrm{H} 1)$.

First, two-step model were conducted for internalizing problems of learning disabled children. In Step 1, internalizing problems were regressed on child gender, age, income level, mothers' education level, duration of marriage. However, only duration of marriage was significant predictor, so others were excluded from the model. In Step 2, specific support resources were added separately.

Only perceived informational support significantly predicted internalizing problems. All other subscales of perceived social support did not significantly predict the child internalizing problems. That's why only the results for informational support were presented.

For perceived informational support, the hierarchical regression revealed that for model 1 , the variable did make significant contribution to the explained variance in the equation, adjusted $R^{2}=.06, F(1,86)=6.54, p<.05$. The effect of duration of marriage negatively predicted $(\beta=-.27, p<.05)$ internalizing problems. In the second step, perceived informational support was added and the results indicated that this variable did account for additional variance in predicting overall internalizing problems, adjusted $R^{2}=.09, F(1,85)=3.75, p<.05$. So, mothers' perceived informational support was a 
significant and negative predictor of internalizing problems $(\beta=-.20, p<.05)$ (see Table 3).

Table 3

Summary of Hierarchical Regression Analysis for Perceived Informational Support Predicting Internalizing Problems (not controlling for learning disability level)

Model 1

\begin{tabular}{lcccccc}
\hline Variables & $B$ & $(S E)$ & $\beta$ & $B$ & $(S E)$ & $\beta$ \\
Duration of marriage & -0.02 & $(0.01)$ & $-.27^{*}$ & -0.02 & $(0.01)$ & $-.26^{*}$ \\
Perceived informational & & & & -0.13 & $(0.07)$ & $-.20^{*}$ \\
support & & & & & & \\
\hline Adjusted $R^{2}$ & & .06 & & & .09 & \\
$F$ & & $6.55^{*}$ & & & $3.75^{*}$ & \\
\hline
\end{tabular}

Notes. $* p<.05$.

3.3.1.2. Results for Internalizing Problems after Controlling for Learning Disability Level

Learning disability level was added to the models and analyses were repeated after controlling learning disability level of the child (H2).

Two-step model were repeated for perceived informational support in predicting internalizing problems of learning disabled children after adding learning disability level as a controlling variable. The hierarchical regression revealed that for model 1 , duration of marriage and learning disability level did make significant contribution to the explained variance in the equation, adjusted $R^{2}=.09, F(2,86)=5.53, p<.05$. While the effect of duration of marriage negatively and marginally predicted $(\beta=-.20, p<$ $.10)$, learning disability level significantly and positively predicted $(\beta=.23, p<.05)$ internalizing problems. In the second step, perceived informational support was added and the result indicated that this variable did marginally account for additional variance in predicting overall internalizing problems, adjusted $R^{2}=.12, F(1,85)=2.98, p=.08$. 
So, mothers' perceived informational support become a marginal and negative predictor of internalizing problems after adding learning disability to the model $(\beta=-.18, p=.08)$ (see Table 4).

Table 4

Summary of Hierarchical Regression Analysis for Perceived Informational Support Predicting Internalizing Problems (controlling for learning disability level)

\begin{tabular}{|c|c|c|c|c|c|c|}
\hline & \multicolumn{3}{|c|}{ Model 1} & \multicolumn{3}{|c|}{ Model 2} \\
\hline Variables & $B$ & $(S E)$ & $\beta$ & $B$ & $(S E)$ & $\beta$ \\
\hline Duration of marriage & -0.02 & $(0.01)$ & $-.20^{\dagger}$ & -0.02 & $(0.01)$ & $-.21 *$ \\
\hline Learning disability level & 0.19 & $(0.08)$ & $.23 *$ & 0.15 & $(0.01)$ & $-.20^{\dagger}$ \\
\hline $\begin{array}{l}\text { Perceived informational } \\
\text { support }\end{array}$ & & & & -0.12 & $(0.07)$ & $-.18^{\dagger}$ \\
\hline Adjusted $R^{2}$ & & .09 & & & .12 & \\
\hline$F$ & & $5.53 *$ & & & $2.98^{\dagger}$ & \\
\hline
\end{tabular}

Notes. $\dagger \mathrm{p}<.10 . * p<.05 . * * p<.01$.

All in all, it was seen that informational support was a critical perceived support for internalizing problems, and controlling learning disability level decreasing the predictive power of the perceived informational support.

\subsubsection{Hierarchical Regression for Perceived Social Support Resources and Externalizing Problems}

3.3.2.1. Results for Externalizing Problems without Controlling for Learning Disability Level

In line with this theory, hierarchical regression analyses were conducted for each support resource and externalizing problems separately $(\mathrm{H} 1)$. 
First, two-step model was conducted for externalizing problems of learning disabled children. In Step 1, externalizing problems were regressed on child gender, age, income level, mothers' education level, duration of education (in months). However, only duration of education (in months) was significant predictor, so others were excluded from the model. In Step 2, specific support resources were added separately. Perceived emotional, caregiving and financial support were found significant. However, other subscales of perceived social support did not significantly predict the child externalizing problems. That's why only the results for emotional, caregiving and financial supports were presented respectively.

To begin with, for emotional support, the hierarchical regression revealed that for model 1 , the variable did make marginally significant contribution to the explained variance in the equation, adjusted $R^{2}=.03, F(1,86)=3.55, p=.06$. The effect of duration of education positively and marginally predicted $(\beta=.20, p=.06)$ externalizing problems. In the second step, perceived emotional support was added and the result indicated that this variable did significantly account for additional variance in predicting overall externalizing problems, adjusted $R^{2}=.07, F(1,85)=5.14, p<.05$. So, mothers' perceived emotional support was a significant and negative predictor of externalizing problems $(\beta=-.24, p<.05)$ (see Table 5). 
Table 5

Summary of Hierarchical Regression Analysis for Perceived Emotional Support Resources Predicting Externalizing Problems (not controlling for learning disability level)

Model 1

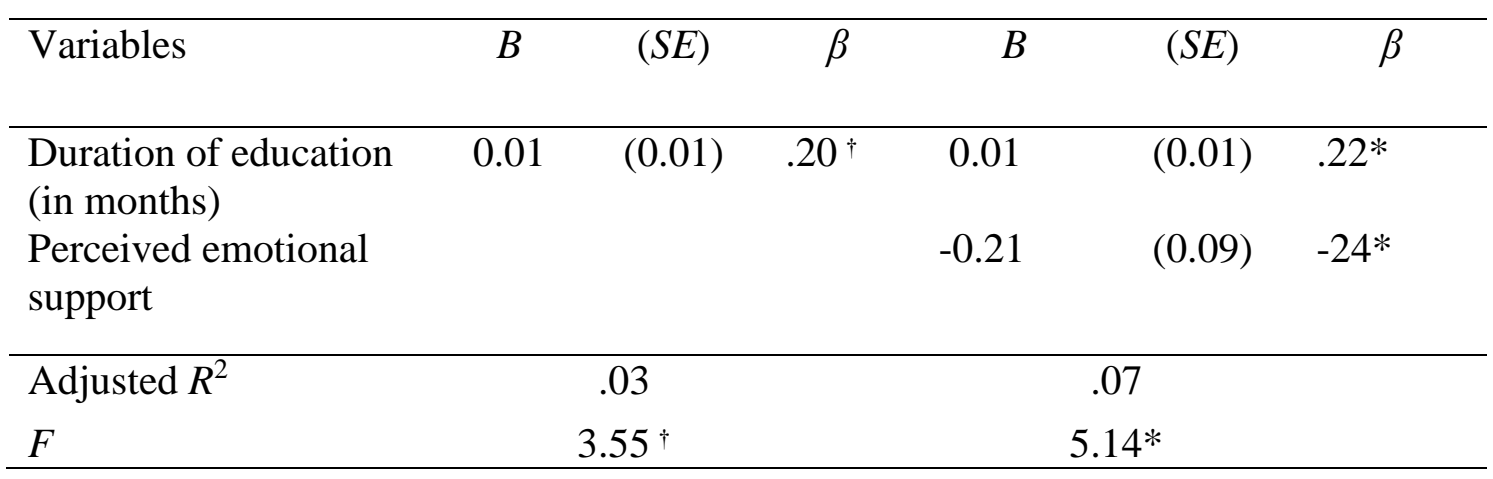

Notes ${ }^{\dagger} p=.06 . * p<.05$.

Moreover, the two-step model for perceived caregiving support was significant. For this analysis, in Step 1, only duration of education (in months) included to the model. The variable did make marginally significant contribution to the explained variance in the equation, $R^{2}=.03, F(1,88)=3.58, p=.05$, and the duration of education (in months) marginally and positively predicted $(\beta=.20, p=.06)$ externalizing problems. At the second step, perceived caregiving support was added and the result indicated that it accounted for additional variance in predicting overall internalizing problems, adjusted $R^{2}=.07, F(1,87)=4.57, p<.05$. The effect of caregiving was significant and negative on externalizing problems $(\beta=-.22, p<.05)$ (see Table 6$)$. 
Table 6

Summary of Hierarchical Regression Analysis for Perceived Caregiving Support Resources Predicting Externalizing Problems (not controlling for learning disability level)

Model 1

\begin{tabular}{lcccccc}
\hline Variables & $B$ & $(S E)$ & $\beta$ & $B$ & $(S E)$ & $\beta$ \\
\hline $\begin{array}{l}\text { Duration of education } \\
\text { (in months) }\end{array}$ & 0.01 & $(0.01)$ & $.20^{\dagger}$ & 0.01 & $(0.01)$ & $.20^{\dagger}$ \\
$\begin{array}{l}\text { Perceived caregiving } \\
\text { support }\end{array}$ & & & & -0.17 & $(0.81)$ & $-.22^{*}$ \\
\hline Adjusted $R^{2}$ & & & & & & \\
$F$ & & .03 & & & .07 & \\
\hline
\end{tabular}

Notes. ${ }^{\dagger} p=.06 .{ }^{*} p<.05 . * * p<.01$.

Next, for perceived financial support, at Step 1, only duration of education (in months) was added to the model. The variable did make marginally significant contribution to the explained variance in the equation, $R^{2}=.03, F(1,88)=3.59, p=.06$, and the effect of duration of education (in months) marginally and positively predicted $(\beta=.20, p=$ .06) externalizing problems. At the second step, perceived financial support was added and the result indicated that it accounted for additional, but marginal variance in predicting overall internalizing problems, adjusted $R^{2}=.05, F(1,87)=2.87, p=.09$. Perceived financial support was marginally and negatively predicted externalizing problems $(\beta=-.18, p=.09)$ (see Table 7). 
Table 7

Summary of Hierarchical Regression Analysis for Perceived Financial Support Resources Predicting Externalizing Problems (not controlling for learning disability level)

Model 1

\begin{tabular}{lcccccc}
\hline Variables & $B$ & $(S E)$ & $\beta$ & $B$ & $(S E)$ & $\beta$ \\
\hline $\begin{array}{l}\text { Duration of education } \\
\text { (in months) }\end{array}$ & 0.01 & $(0.01)$ & $.20^{\dagger}$ & 0.01 & $(0.01)$ & $.18^{\dagger \dagger}$ \\
$\begin{array}{l}\text { Perceived financial } \\
\text { support }\end{array}$ & & & & -0.13 & $(0.07)$ & $-.18^{\dagger \dagger \dagger}$ \\
\hline Adjusted $R^{2}$ & & & & & & \\
$F$ & & .03 & & & & \\
\hline
\end{tabular}

Notes. ${ }^{\dagger} p=.06 .{ }^{\dagger \dagger} p=.07 .{ }^{\Uparrow \dagger} p=.09$.

3.3.2.2. Results for Externalizing Problems after Controlling for Learning Disability Level

Learning disability was added to the models in the first step in order to control its effect and analyses were repeated after controlling learning disability level of the child (H2). Then, none of the subscales of perceived social support did predict the child externalizing problems after controlling learning disability level. However, there was an unexpected result for perceived emotional support. Because when learning disability level was included in the model, for caregiving and financial support, only disability level explained the variance of predicting externalizing problems. For emotional support, however, both emotional and learning disability level become non-significant in the model. Therefore, for emotional support, it was suspected that there might be an interaction effect between perceived emotional support and learning disability level. To investigate a possible interaction effect further, a third step of interaction was added to the model. That's why only the results for emotional support were presented. 
With regard to perceived emotional support, the hierarchical regression revealed for step 1 that both variables did make significant contribution to the explained variance in the equation, adjusted $R^{2}=.05, F(1,87)=3.27, p<.05$. While duration of education positively predicted $(\beta=.25, p<.05)$, learning disability level positively and marginally predicted $(\beta=.21, p=.06)$ externalizing problems. At the second step, perceived emotional support was added and the result indicated that this variable wasn't a significant predictor of externalizing problems $(\beta=-.17, p>.05)$ anymore, but the whole model account for additional variance in predicting overall externalizing problems, adjusted $R^{2}=.07, F(2,85)=2.68, p<.05$.

Although both emotional support and learning disability level were significant predictors of externalizing problems as known before, it was found that the relations become non-significant. To inspect for a possible moderation effect, the interaction of child learning disability level and emotional support was added to the model as a third step. The model was found to be marginally significant, adjusted $R^{2}=.09, F(2,85)=$ $3.44, p=.06$ (see Table 8).

Then, in order to see how this interaction has taken place, a test of simple slope with recently introduced by Hayes (2013) was run and indicated that perceived emotional support tended to be a negative predictor of externalizing problems for children showing mild $(-1 S D)$ difficulties in learning disability $(-.7193, S E=.14, p=.01)$. Also, the relation was negative for children showing average difficulties in learning disability $(.0009, S E=.09, p<.05)$. In contrast, although for mild and average scores it seemed to be a negative predictor, for children showing severe $(+1 S D)$ difficulties in learning disability score, the relation was not significant $(-.7212, S E=.11, p=.73$ ) (see Figure 3). Therefore, when the child shows severe difficulties in learning disability, the effect of perceived emotional support tends to disappear. 
Table 8

Summary of Hierarchical Regression Analysis for Perceived Emotional Support Resources Predicting Externalizing Problems (controlling for learning disability level)

\begin{tabular}{|c|c|c|c|c|c|c|c|c|c|}
\hline & \multicolumn{3}{|c|}{ Model 1} & \multicolumn{3}{|c|}{ Model 2} & \multicolumn{3}{|c|}{ Model 3} \\
\hline Variables & $B$ & $(S E)$ & $\beta$ & $B$ & $(S E)$ & $\beta$ & $B$ & $(S E)$ & $\beta$ \\
\hline $\begin{array}{l}\text { Duration of } \\
\text { education } \\
\text { (in months) }\end{array}$ & 0.01 & $(0.01)$ & $.25^{*}$ & 0.01 & $(0.01)$ & $.24 *$ & 0.01 & $(0.01)$ & $.25^{*}$ \\
\hline $\begin{array}{l}\text { Learning } \\
\text { disability } \\
\text { level }\end{array}$ & 0.21 & $(0.11)$ & $.21^{\dagger}$ & 0.18 & $(0.11)$ & .17 & 0.19 & $(0.11)$ & $.19^{\dagger}$ \\
\hline $\begin{array}{l}\text { Perceived } \\
\text { emotional } \\
\text { support }\end{array}$ & & & & -0.15 & $(0.09)$ & -17 & -0.22 & $(0.01)$ & $-.21 *$ \\
\hline Interaction* & & & & & & & 0.22 & $(0.12)$ & $.19^{\dagger}$ \\
\hline Adjusted $R^{2}$ & & .05 & & & .07 & & & .09 & \\
\hline$F$ & & $3.27 *$ & & & $2.68 *$ & & & $3.44^{\dagger}$ & \\
\hline
\end{tabular}

Notes ${ }^{\dagger} p=.06 . * p<.05 . * * p<.01$. *Interaction of learning disability and perceived emotional support. 


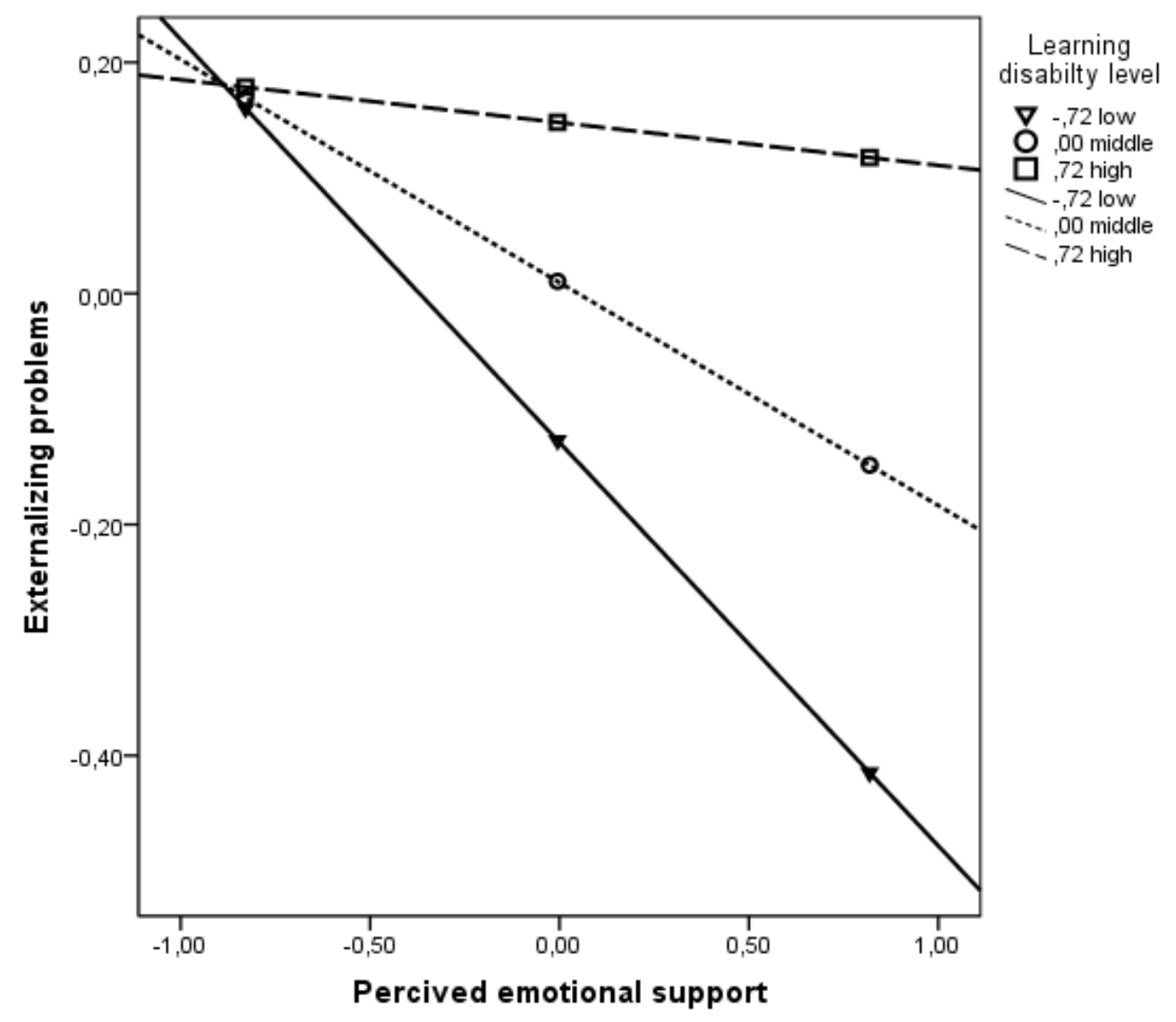

Figure 3. The Interaction between Child Learning Disability Level, Mother Perceived Emotional Support and Externalizing Problems

In conclusion, although support was a crucial factor, child's learning disability level seemed to be an important predictor and decreasing the effect of support in explaining the child externalizing behavior.

\subsubsection{Hierarchical Regression for Values and Perceived Social Support}

As line with hypothesis 3, it was expected that mothers who have high scores in both openness to change and conservation values' scales would positively predict mother's perceived support resources (caregiving support, emotional support, informational support, intimate relations support and financial support), after controlling the child learning disability level (H3). Therefore, the regression analyses were conducted. 
First, three-step model was conducted for specific support resources. In Step 1, supports were regressed on income level, mothers' education level, and learning disability level (only these variables were correlated with the outcome see Table 2). In Step 2, conservation and openness to change values were added separately in models. Finally, the interaction of both values was added in Step 3.

However, conservation values, openness to changes values and the interaction of values (internalizing both values) did not predict perceived caregiving support, emotional support, informational support, intimate relations support and financial support after controlling learning disability level.

\subsubsection{Hierarchical Regression for Values and Internalizing Problems}

As line with hypothesis 4 , the relationship between values and problem behaviors of learning disabled children was inspected. So, three-step hierarchical regression analyses were conducted for internalizing problems. Learning disability was controlled in order to see direct effect of values on the problem behaviors.

In Step 1, internalizing problems were regressed on income level, mothers' education level, duration of marriage and learning disability level (only these variables were correlated with the outcome see Table 2). However, only learning disability level was a significant predictor, so others were excluded from the model. In Step 2, openness to change and conservation values were added. Finally, the interaction of both values was added in Step 3.

As seen in the Table 9, interaction of both values tended to predict the internalizing problems. Child learning disability was included in the first model because it was only a significant predictor as mentioned before. For model 1, the hierarchical regression revealed that child learning disability level explained $7 \%$ of the variance in internalizing problems, adjusted $R^{2}=.07, F(1,87)=7.24, p<.01$. The effect of learning disability level $(\beta=.28, p<.01)$ was positive and significant in predicting internalizing problems. For the second step, openness to change and conservation values were included to 
hierarchical regression, however it didn't explain the variance of internalizing problems, adjusted $R^{2}=.05, F(2,85)=0.02, p=.98$. Besides, in the third step, when interaction of both values were added, interaction marginally and negatively predicted internalizing problems, but it did not increase the explained variance, adjusted $R^{2}=.07, F(1,84)=$ $3.23, p=.07$.

Then, in order to examine this interaction further, a test of simple slope with recently introduced by Hayes (2013) was run. The results demonstrated that it tended to be a positive relation between internalizing problems and openness to change for mother who have low $(-1 S D)$ conservation values $(-.6016, S E=.11, p=.28)$. However, the relation seemed to become negative for people in average score in conservation (.0029, $S E=.10, p=.55)$. Also, the results demonstrated that it tended to be a negative relation between internalizing problems and openness to change values when mothers have high $(+1 S D)$ in conservation values $(-.6674, S E=.12, p=.32$ ) (see Figure 4). In other words, when mothers internalized both values, the internalizing problems tended to be lowest in learning disabled children. 
Table 9

Summary of Hierarchical Regression Analysis for Mothers' Values Predicting Internalizing Problems

\begin{tabular}{|c|c|c|c|c|c|c|c|c|c|}
\hline & \multicolumn{3}{|c|}{ Model 1} & \multicolumn{3}{|c|}{ Model 2} & \multicolumn{3}{|c|}{ Model 3} \\
\hline Variables & $B$ & $(S E)$ & $\beta$ & $B$ & $(S E)$ & $\beta$ & $B$ & $(S E)$ & $\beta$ \\
\hline $\begin{array}{l}\text { Learning } \\
\text { disability level }\end{array}$ & 0.22 & $(0.08)$ & $.28 * *$ & 0.23 & $(0.09)$ & $.28 * *$ & 0.20 & $(0.09)$ & $.25^{*}$ \\
\hline $\begin{array}{l}\text { Openness to } \\
\text { change }\end{array}$ & & & & 0.02 & $(0.10)$ & .02 & 0.01 & $(0.10)$ & .01 \\
\hline Conservation & & & & 0.01 & $(0.10)$ & .00 & -0.07 & $(0.11)$ & -.08 \\
\hline Interaction $* * *$ & & & & & & & -0.19 & $(0.11)$ & $-.20^{\dagger}$ \\
\hline Adjusted $R^{2}$ & & .07 & & & .05 & & & .07 & \\
\hline$F$ & & $7.24 * *$ & & & 0.02 & & & $3.23^{\dagger}$ & \\
\hline
\end{tabular}

Notes. ${ }^{\dagger} \mathrm{p}=.07 .{ }^{*} \mathrm{p}<.05 .{ }^{*} \mathrm{p}<.01 . * * *$ Interaction between openness to change and conservation values 


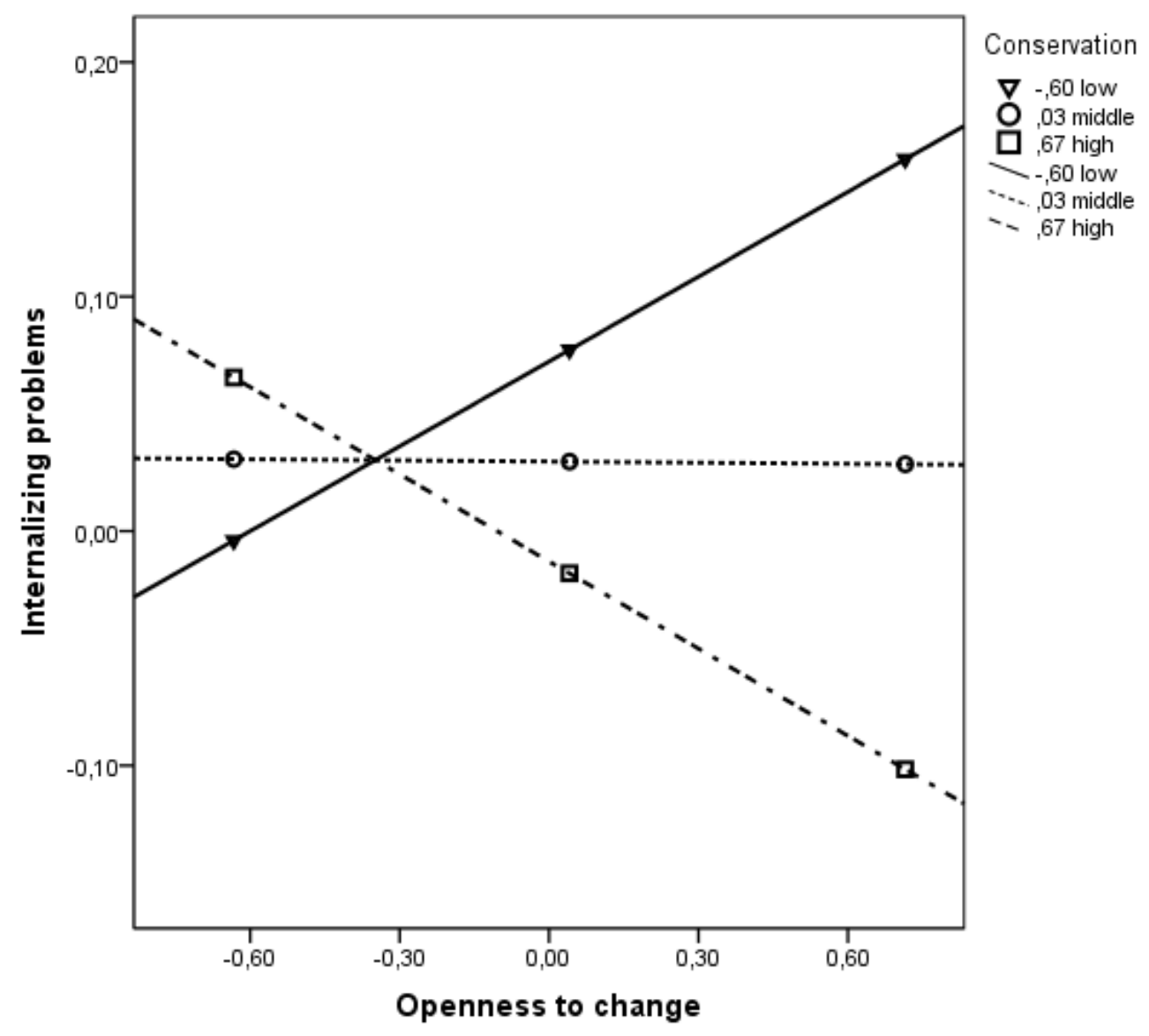

Figure 4. The Interaction between Mothers' Values and Internalizing Problems

\subsubsection{Hierarchical Regression for Values and Externalizing Problems}

The three-step hierarchical regression analysis was carried for also externalizing problems. In Step 1, duration of education (in months) for externalizing problems were entered because this variable significantly predicted outcome variable and also child learning disability level was included. In Step 2, openness to chance and conservation values were added. Finally, the interaction of both values was added in Step 3. However, there was no relationship between mother's values and externalizing problems, adjusted $R^{2}=.01, F(1,80)=0.20, p=.89$. 


\section{CHAPTER IV}

\section{DISCUSSION}

The aim of the present study was to examine the relationship among mothers' perceived social support resources, values and child problem behaviors. The findings were discussed considering each independent variable separately (perceived social support resources and mothers' values). After discussing main findings, limitations and suggestions, and implications of the study were presented. Finally, a conclusion was given.

\subsection{EVALUATION OF CORRELATIONS BETWEEN STUDY VARIABLES}

The Pearson correlations of the variables indicated remarkable findings. First, specific support resources except informational support were positively correlated with income. All of the support resources were correlated with education level. So, disabled children's families may attain support resources more easily than people with low income and education level. As findings of previous studies also indicated that poverty or low socioeconomical level related low attainment of support resources (Brookins, 1993; Rothman \& Cosden, 1995).

Second, the duration of education (in months) and duration of marriage was negatively related with child learning disability level and internalizing problems. For duration of special education, there was a consensus about positive effect of special education on especially for learning disabled children. However, it should be noted that the learning disabled children have reading disability for two or three years even after applying interventions including special education strategies (Lyon, 1996). Thus, instead of duration, in the literature the quality of education (e.g. not using general instruction or inappropriate materials in the lessons) and education given by specialized teachers for child improvement is more emphasized (Lyon, 1996; Undehim, 2002). Similarly, compared to duration of marriage (Tak \& McCubbin, 2002), quality of it seems to be 
more critical for children development (Bristol et al., 1988; Hassall et al., 2005; Heiman $\&$ Berger, 2008). As a whole, although these variables seem to be helpful for families to deal with the disability, their qualities should also be assessed in further analysis.

Besides, duration of education was positively correlated with externalizing problems. Therefore, children who have externalizing problems at the onset of attaining special education may continue to demonstrate these problems. On the contrary, since there is no information about children level of externalizing problems when they started to special education, this finding requires further replication before further interpretation. However, although it was an anticipated result, duration of education was controlled in regression analysis of externalizing problems due to significant correlation between them.

Furthermore, different types of support resources seem to be differentially critical for child problem behaviors, and as the mother perceived specific social support decreases, the child seems to show more externalizing (emotional, caregiving and financial support), and internalizing (informational support) problems. This was consistent with the literature, as the main assumption of the ecocultural theory (Nihira et al., 1994).

More, there was a negative correlation between learning disability level total score and mothers' perceived social support resources (emotional, intimate relations, informational, caregiving support). Lack of social network negatively affect child disability (Wagner \& Blackorby, 1996). Hence, the child may have less chance to attain to the services, so this may negatively influence the child.

Last, in this study, values were not correlated with perceived support resources. Although, there were studies indicating relationship between social support and values in the literature (Goodwin et al., 2004; Feather et al., 2012; Triandis et al., 1985), no relationship was found in the current study. Besides, conservation values were not correlated with both problem behaviors. On the other side, openness to change values were marginally correlated with only externalizing problems. 


\subsection{EVALUATION OF PREDICTORS OF CHILD PROBLEM BEHAVIORS}

\subsubsection{Findings for Perceived Social Support Resources and Internalizing Problems}

The first goal of the study was to investigate whether perceived specific support resources would predict child problem behaviors. In the current study results indicated that perceived informational support negatively predicted internalizing problems, however it only marginally and negatively predicted after controlling for learning disabled level. In literature, it was mainly argued that information and support taken from professionals were generally inadequate in these families (Sandy et al., 2013; Tews \& Merali, 2008). More, this support especially argued to be important in dealing with behavioral, educational and emotional needs of the children (Greenspan, 2004; Hodapp, Dykens, \& Masino, 1997). In other words, when parents take informational support about the child, they may create a more supportive environment for the child. In turn, the child's self-perception may become more positive.

To answer why this support was only related with internalizing problems imposes a critical point. To authors' knowledge, there were no studies found showing a direct relation between perceived informational support and internalizing problems. One possible explanation of this finding is that, according to Gottman, Katz, and Hooven's study (1995) conducted with normally developing children and their families, maternal coaching (e.g. being aware of child emotion, help the child to learn the ability to deal with their emotions in a supportive manner) was related with teachers' reports of low levels of internalizing problems, but not related with externalizing behaviors. Gottman et al. (1996) stated that parental coaching does not simply promote children's expressing their emotions (e.g. express aggression), rather parental coaching encourages children to control their negative feelings and emotions (e.g. anxiety), to calm down and focus their attention (Eisenberg et al., 2001). So, children learn when they control and express their emotions. In all, parental coaching promotes the child to express their feelings rather than uncontrolled expression of emotions as seen in externalizing problems. 
Although this study was conducted with normally developing children, the same could be also applied to learning disabled children. Researchers argue that parents had limited information about the child disability and prognosis (Sandy et al., 2013). So, perceived informational support could help parents how to effectively deal with disability and to understand child emotions related to learning disability. This may result in guiding the child about regulating their negative emotions and learn to express their feelings, which in turn result in lower internalizing problems. This support seems to be additionally critical in learning disabled children, because in the current study, it was still marginally significant even after controlling for learning disability level. As a result, it can be concluded that informational support is a critical type of support resource for these families and children, and this support should be taken into account in studies and interventions.

\subsubsection{Findings for Perceived Social Support Resources and Externalizing Problems}

In the current study, perceived emotional and caregiving support significantly, and financial support marginally predicted externalizing problems, but none of them predicted externalizing problems after controlling learning disability level. Nevertheless, only the interaction of perceived emotional support with learning disability level marginally predicted externalizing problems.

In the literature, it was stressed that emotional, financial and caregiving support resources were crucial for learning disabled children (Brookins, 1993; Sandy et al., 2013; Wagner \& Blackorby, 1996). However, although the relation between specific support resources and child development was studied in developmental delayed children (Nihira et al., 1994), it was not studied in detail in the learning disabled children literature.

To begin with, perceived emotional support in the family negatively predicted child externalizing behaviors in this study. In literature, it was stressed that caregivers of learning disabled children needed emotional support (Sandy et al., 2013), and cohesion 
and support in the family structure influenced child problem behaviors (Morisson \& Cosden, 1997). On the other hand, to authors' knowledge there were no studies found that indicated direct relationship between mothers' perceived emotional support and child externalizing problems. In the learning disability literature, the relation between total social support score and child outcomes was mainly studied instead of specific support resources such as emotional support. Therefore, why mothers' perceived emotional support was only related with externalizing problems imposes a critical point.

This finding could be explained through an indirect path. In detail, expressing emotions is likely to be related with parent's positive expressivity with the child in the family context (Bristol et al., 1988; Eisenberg et al., 2000). In other words, since caregivers of learning disabled children reported that they had feelings of anger, frustration and helplessness (Sandy et al., 2013), expressing negative feelings to their friends, family members or receiving emotional support may lead parents to calm down or help them to regulate their negative feelings (Belsky, 1984). Because these mothers have the opportunity to share their negative emotions with their friends or relatives, they will be better in coping with the stress associated with the disability. In turn, these mothers may create a warm environment for their disabled children.

For example, in normally developing children, researchers found that parent's emotional support (e.g. warmth) negatively predicted children externalizing problems, but not internalizing problems in the family context (Eisenberg et al., 2001; Mccarty et al., 2005). According to Eisenberg et al. (2000), while warm parenting generally had been positively related to children's adjustment, and especially low levels of aggression, parental negativity had indicated the reverse pattern of the relation. Thus, children growing in a warm and supportive environment may tend to be more emotionally secure and therefore less prone to externalizing problems (Cummings \& Davies, 1996, as cited in Eisenberg et al., 2001; Mccarty, Zimmerman, Digiuseppe, \& Christakis; 2005).

Although these studies conducted with normally developing children, emotional support seemed to be also crucial for learning disabled children because learning disability is known to be a stressful condition for these families (Antshel \& Joseph, 2006). 
Therefore, perceived emotional support from significant others might help mothers to deal with both her and the child's unregulated emotions such as aggression.

On the other hand, when learning disability level was added to the model, an interaction between perceived emotional support and learning disability level was detected. The path of the relation between learning disability level and emotional support showed that when the disability level was increasing, perceived emotional support effect on externalizing problems seems to disappear. In other words, for children showing severe symptoms, the effect of emotional support becomes non-significant. This finding indicated that even support is effective in mild and moderate level of disabled children, when the situation becomes more complicated or resistant, emotional support for mother wasn't sufficient in dealing with externalizing problems of children.

Second, perceived caregiving support significantly and financial support marginally predicted child externalizing problems when child learning disability level was not controlled. This finding was in line with literature (Dunst et al., 1988; Nihira et al., 1994; Waggoner \& Wilgosh, 1990). Similar to emotional support, parents who take help in child care would having more time for their work related activities, in turn decreasing their sense of isolation. Also, financial support would create the chance for the child in attaining services such as additional educational help or help in satisfying daily needs of the child. With the decrease in financial or child care related stress, these mothers may focus more on the disability and cope better with child externalizing problems. Although these findings were consistent with literature, these studies did not control disability level. In the current study, perceived caregiving and financial support did not predict child problem behaviors after learning disability level was controlled.

Furthermore, contrary to literature (Bristol et al., 1988), intimate relations support did not predict child problem behaviors in the current study. To explain this finding, it can be stated that both parents were exposed to the same situation within the family. The role of intimate relations is not rejected, but it is agreed with Dunst et al. (1988) proposal that external support resources may be more critical for them in coping with 
disability. Hence, the support taken from others may increase family members' wellbeing, in turn positively affecting the child.

In sum, when the learning disability level was included to the analysis, the predictive power of the supports on child problem behaviors both decreased and/or become nonsignificant. Thus, there are some points that should be underlined. First, although support might be a protective factor for families and child problem behaviors, disability level seems to be also a prominent predictor of problem behaviors in these children. Second, other services such as psychological help, more effective educational strategies such as intensive instruction of appropriate duration provided by trained teachers might be more critical than social support resources for mothers in dealing with problem behaviors when children show severe symptoms. Similarly, Lyon (1995) claimed that focusing on individual needs of students may be a more effective approach to meet the wide range of needs, choices and abilities of students who participate in special education when they have severe symptoms. Last, this finding shows the important role of learning disability level especially when the relation among familial or contextual factors and child outcomes are investigated. So, it might be a good strategy to add child disability level to the analysis.

\subsubsection{Findings for Values}

Before the evaluation of the findings for values, some points about the values should be emphasized. First, values are abstract concepts. Second, the values' scale includes double-barreled items. As a result, it could be difficult for participants both to interpret the scale and to make a decision for double-barreled items. As a matter of the fact, when the value scale was filled by the participants, they experienced both of the challenges. One of the reason could be the low socioeconomic status of the mothers in the current study. However, despite these limitations, the portrait values questionnaire is a popular and mostly used scale in the literature in measuring individuals' values. Thus, the scale was used in the current study and the findings were evaluated in this part. 
4.2.3.1. Evaluation of the Findings about Values and Perceived Social Support Resources

In contrast to hypothesis 3 and literature (Goodwin et al., 2004; Feather et al., 2012; Triandis et al., 1985), values didn't predict perceived support resources. There could be several reasons. First, the relatively small sample size that leaded attenuation in the sizes of correlation coefficients may be one of the factors. Second, children with learning disability is a specific group. Therefore, the factors that determine these families' support resources can be related to other factors. For example, poverty and economic problems were seen the crucial factors in attaining services (Brookins, 1993; Sandy et al., 2013). As a result, this assumption may be replicated in future studies both with a greater sample size, different economic status or comparison groups (e.g. intellectual disability, autism, physical disabilities, attention deficit hyperactivity disorder).

\subsubsection{Evaluation of the Findings about Values and Internalizing Problems}

In this study, the relationship between values and problem behaviors of learning disabled children was inspected. It was found that neither conservation nor openness to change values leaded to internalizing problems in children. However, in the case of coexistence of both values, children showed less internalizing problems whose mothers have high scores as hypothesized, even after learning disability level was controlled.

As mentioned before, one side of the literature findings emphasize coexistence of values. Especially, Kağıtçıbaşı's (1996) model of family change suggests that with socioeconomical development, decreasing material interdependencies resulted in the families to adapt changes, and allowed autonomy to emerge with relatedness in self and family. Also, Kağıtçıbaşı (2007) stressing that generally Turkey's family model was fitted more in psychological/emotional interdependence. As a result, mothers who internalized both individualistic and collectivistic values would positively influence learning disabled child problem behaviors. To authors' knowledge, there were no studies that investigated the effect of parental values in this specific group. 
This finding about the relation between values and internalizing problems is also in line with the earlier works with normally developing children (Kağıtçıbaşı, 2009; Rudy \& Grusec, 2001; 2006), indicating both promotion of autonomy and relatedness in psychological/emotional interdependent families. Rudy and Grusec (2001) findings supported this view indicating that authoritarian parenting was less likely to be related with negative parental affect and negative interpretations of children's behaviors in Egyptian Canadian families. The reason was that in these families authoritarianism did not mean low levels of parental warmth or more negative attributions about discipline in child rearing anymore. In congruent with their study, it can be concluded that mothers who internalized both values might have better coping orientation in childrearing, and in turn positively influencing their children.

Heiman and Berger (2008) argued that parents of learning disabled children may be more rigid, less open to change and have difficulties in adapting to increased demands related to learning disabled children such as the challenges brought about by learning disability (lower academic achievement). This may lead to dysfunction of family and negatively influencing the child (Morisson \& Cosden, 1997). As found in this current study, mothers who have internalized both values may provide a supportive environment for their children. To explain, internalization of openness to change values was found to support the child autonomy, in turn children can express their feelings more easily in the family context (Kağıtçıbaşı, 2009). Additionally, internalization of conservation (relatedness) values that is maintaining close ties will provide a supportive environment for the child and help the family members to cope with increased demands of the disability. In all, this environment is speculated as an optimal environment for a child with a learning disability as it promotes more flexibility in the case of changes and healthy growth.

\subsubsection{Evaluation of the Findings about Values and Externalizing Problems}

Contrary to internalizing problems, there was no relationship found between values and externalizing problem behaviors. In the literature, externalizing problems were seen mostly when attentional problems and/or hyperactivity comorbid, and learning 
disability is more related with internalizing problems rather than externalizing problems (Batum \& Öktem, 2010; Willcutt \& Pennington, 2000). To illustrate, Batum and Öktem (2010) found that there were more externalizing problems in learning disabled children who also diagnosed with attention deficit hyperactivity disorder. However, the same pattern was not seen for internalizing problems. Also, when attention deficit hyperactivity disorder was controlled, the relation between learning disability and externalizing problems disappears (Willcutt \& Pennington, 2000), but not for the relation between internalizing problems and learning disability. However, attention deficit hyperactivity disorder could be a confounding variable in predicting externalizing problems because the observed behaviors in attention deficit hyperactivity disorder are also mostly measured in externalizing problems scales. Therefore, in these children externalizing problems were likely to be observed more than internalizing problems.

In all, it was speculated that since comorbid cases were excluded from the analyses externalizing problems were observed less than internalizing problems in the current study. Thus, comorbidity of other diagnoses, child severity or other unknown variables rather than values may explain or could be underlying factor for externalizing problems.

\subsection{LIMITATIONS AND SUGGESTIONS}

Although the current study has contributed to the current literature regarding learning disabled children, the study has some limitations that should be taken into consideration when interpreting the findings and when planning the future research.

To begin with, the sample size of the present study was small. A larger sample size would increase the power to test more complex models. However, the sample size of the learning disability studies in the existing literature also changes between 10 to 125 , and it was seen that only two studies included about 200 learning disabled children according to one metanalysis findings (Nelson \& Harwood, 2011). However, when the sample size of these studies was considered, sufficient number of students tried to be included in the present study. 
Second, families were reached by using convenience sampling method, and behavioral problems information was taken from teachers via mothers, resulting in a smaller sample size of teacher's reports than mothers' reports.

Third, by its definition, values are socially desirable characteristics. Thus, the feature of values may result in ceiling effect in the variable distributions. Such distributions may result in diminishing in the sizes of correlation coefficients and predictive power of values. Also, since the items of the scale are abstract in nature, it might make it harder to interpret the scale for the mothers in the current study. Similarly, Demirutku and Sümer (2010) found low Cronbach's alpha coefficients in openness to change values (.56 for self-stimulation and .58 for self-direction) in Turkish sample, as in our study (.53 for openness to change values). As all, it is suggested that future research should take a more suitable approach in assessment of values.

Next, as this study was not longitudinal, conclusion cannot be made about cause and effect. Replication of this study including longitudinal component will be necessary to assess the cause and effect relationship between the variables.

Last, a more diverse sample would be useful to explore our findings further (e.g. intellectual disability, autism). Such a replication would indicate whether these results seen in this study are unique to learning disability or whether they can be generalized to other groups.

In sum, future research would benefit from exploring different demographic variables (e.g. marital status, birth order etc.) across different groups, over time and in larger sample size.

\subsection{IMPLICATION}

The main contribution of the present study is to provide empirical evidence on the relationship between contextual factors and child problem behaviors of learning disabled children. Although academic, psychopathological, social, emotional and 
cognitive development of learning disabled children were studied in the literature, to author's knowledge, there are no studies investigating the relationship between coexisting values and specific perceived social support resources for learning disabled children. Especially in Turkey, mostly the academic achievements, adjustment, parent's stress, depression, support of learning disabled children are studied. It was the first time that not only behavioral problems and familial support resources of learning disabled children, but also the relationship between mothers' cultural values and child outcome was studied. Based on the current findings related to learning disabled children, both family perceived support resources (especially informational, emotional, caregiving and financial support) and parent's values are crucial, and provides opportunity for better developmental outcomes of the learning disabled child. This is also the main point that the Ecocultural theory is stressing.

Furthermore, the effect of the support seems to decrease after controlling learning disability level, and other factors that may be effective in the prognosis of learning disability should be also investigated. Intervention programs should include additional educational, behavioral and psychosocial help especially for children showing more severe symptoms. Also, the quality and effectiveness of interventions such as being sensitive to child abilities and difficulties is a critical point for children development (Lyon, 1996). Besides, future research may benefit including learning disability level when examining relationship between predictor and outcome variables.

In addition to support resources, cultural factors seemed to be important predictor in child problem behaviors, and the study findings contributed to literature by considering learning disability from ecocultural perspective. So, as stressed in ecocultural theory, family is living in a specific context and this cultural context influence family daily living and practices, and also child developmental outcomes. This study partially supported this claim of the theory even after the child learning disability level was controlled. Findings for values indicated that the importance of a culturally sensitive understanding of concepts can help researches to develop more effective prevention and intervention programs. 
Further, cultural norms and values shape the parents' views of the development of their children. The findings are consistent with many developmental theories that emphasize the within cultural differences and the effect of culture on child development (Bronfenbrenner, 1986; Super, \& Harkness, 1986; Kağıtçıbaşı, 1996; Weisner, 2002a, Bornstein, 2011).

Finally, assessing the relations with multiple informants enabled to take different perspectives into account and helped to capture a more comprehensive picture. In addition to showing different perspectives, multiple informants helped to eliminate a possible single source bias.

\subsection{CONCLUSION}

To authors' best knowledge, this current study is one of the first studies that investigate the relationships among cultural factors (values), familial factors (specific supports) and learning disabled children problem behaviors. Also, findings add to our understanding of the role of support in learning disabled child outcomes by: (1) determining the importance of including different support resources, (2) providing partial evidence for the effect of coexistence of values, (3) demonstrating the importance of including child learning disability level in analysis, (4) suggesting the crucial effect of cultural and individual factors on child development. 


\section{REFERENCES}

Akınc1, B. (2011). Özgül ögrrenme güçlüğü gösteren çocuklarda öz-kavramı, algılanan sosyal destek ve sosyo-demografik değişkenlerin incelenmesi (Master thesis). Retrieved from Ulusal Tez Merkezi. (296640)

Al-Yagon, M., \& Mikulincer, M. (2004). Socioemotional and academic adjustment among children with learning disorders the mediational role of attachment-based factors. The Journal of Special Education, 38(2), 111-123.

Al-Yagon, M. (2012). Adolescents with learning disabilities: Socioemotional and behavioral functioning and attachment relationships with fathers, mothers, and teachers. Journal of Youth and Adolescence, 41(10), 1294-1311.

American Psychiatric Association. (2013). Diagnostic and statistical manual of mental disorders (5th ed.). Washington, DC: 31-87.

Antshel, K. M., \& Joseph, G.-R. (2006). Maternal stress in nonverbal learning disorder: a comparison with reading disorder. Journal of Learning Disabilities, 39(3), 194205. http://doi.org/10.1177/00222194060390030101

Atalay, D. Ö. (2013). Özgül öğrenme güçlüğü tanılı çocuğa sahip annelerin algılanan sosyal destek düzeylerinin ve stresle başa çıkma tutumlarının incelenmesi (Master thesis). Retrieved from Ulusal Tez Merkezi. (332625)

Batum, P. (2007). Öğrenme bozukluklarında ebeveyn kabulü/reddi ile içselleştirme ve dışsallaştırma sorunlarının incelenmesi (Master thesis). Retrieved from Ulusal Tez Merkezi. (138317)

Batum, P., \& Öktem, F. (2011). Parental acceptance-rejection, internalizing and externalizing behavior problems in children with learning disabilities. Çocuk ve Gençlik Ruh Să̆lı̆̆ Dergisi/Turkish Journal of Child and Adolescent Mental Health, 18(1), 5-19.

Bauminger, N., \& Kimhi-Kind, I. (2008). Social information processing, security of attachment, and emotion regulation in children with learning disabilities. Journal of Learning Disabilities, 41(4), 315-332. 
Baumrind, D. (1971). Current patterns of parental authority. Developmental Psychology, 4(1, Pt.2), 1-103. doi:10.1037/h0030372

Belsky, J. (1984). The determinants of parenting: A process model. Child Development, 83-96.

Belts, A. L. (2011). Treatment effectiveness for LD and ADHD. In Goldstein, S., Naglieri, J. A., \& DeVries M (Eds.), Learning and attention disorders in adolescence and adulthood: assessment and treatment (pp. 343-363). New Jersey, NJ: John Wiley \& Sons, Inc.

Bernheimer, L. P., Gallimore, R., \& Weisner, T. S. (1990). Ecocultural theory as a context for the individual family service plan. Journal of Early Intervention, 14(3), 219-233.

Bonifacci, P., Storti M., Tobia V., \& Suardi, A. (2015). Specific learning disorders: a look inside children's and parents' psychological well-being and relationships. Journal of Learning Disabilities, 1-14.

Bornstein, M. H. (2012). Cultural approaches to parenting. Parenting, 12(2-3), 212221. http://doi.org/10.1080/15295192.2012.683359

Bristol, M. M., Gallagher, J. J., \& Schopler, E. (1988). Mothers and fathers of young developmentally disabled and nondisabled boys: Adaptation and spousal support. Developmental Psychology, 24(3), 441.

Bronfenbrenner, U. (1986). Ecology of the family as a context for human development: Research perspectives. Developmental Psychology, 22(6), 723-742. http://doi.org/10.1037/0012-1649.22.6.723.

Brookins, G. K. (1993). Culture, ethnicity, and bicultural competence: Implications for children with chronic illness and disability. Pediatrics, 91(5), 1056-1062.

Chang, J. (2015). The interplay between collectivism and social support processes among Asian and Latino American college students. Asian American Journal of Psychology, 6(1), 4.

Craig, G. J. (1999). Human development. Englewood Cliffs, NJ, US: Prentice-Hall, Inc. Cantwell, J., Muldoon, O. T., \& Gallagher, S. (2014). Social support and mastery 
influence the association between stress and poor physical health in parents caring for children with developmental disabilities. Research in Developmental Disabilities, 35(9), 2215-2223.

Daley, T. C., \& Weisner, T. S. (2003). "I speak a different dialect": Teen explanatory models of difference and disability. Medical Anthropology Quarterly, 17, 25-48. doi: 10.1525/maq.2003.17.1.25

Damon, W., \& Lerner, R. M. (2008). Child and adolescent development: An advanced course. (Ed.) New Jersey, NJ: John Wiley \& Sons Inc.

Demirutku, K. (2004). Turkish adaptation of the portrait values questionnaire. Unpublished manuscript, Department of Psychology, Middle East Technical University, Ankara.

Demirutku, K. (2007). Parenting styles, internalization of values, and the self-concept (Doctoral dissertation). Retrieved from Ulusal Tez Merkezi. (218027)

Demirutku, K., \& Sümer, N. (2010). Temel değerlerin ölçümü: Portre Değerler Anketi'nin Türkçe uyarlaması. Türk Psikoloji Yazıları, 13(25), 17-25.

Denham, S. A., Workman, E., Cole, P. M., Weissbrod, C., Kendziora, K. T., \& ZahnWaxler, C. (2000). Prediction of externalizing behavior problems from early to middle childhood: The role of parental socialization and emotion expression. Development and Psychopathology, 12(01), 23-45.

Dunst, C. J., Leet, H. E., \& Trivette, C. M. (1988). Family resources, personal wellbeing, and early intervention. The Journal of Special Education, 22(1), 108-116.

Dyson, L. L. (2003). Children with learning disabilities within the family context: A comparison with siblings in global self-concept, academic self-perception, and social competence. Learning Disabilities Research \& Practice, 18(1), 1-9.

Eisenberg, N., Losoya, S., Fabes, R. A., Guthrie, I. K., Reiser, M., Murphy, B., ... \& Padgett, S. J. (2001). Parental socialization of children's dysregulated expression of emotion and externalizing problems. Journal of Family Psychology, 15(2), 183.

Erden, G. (2016). Özgül Öğrenme Güçlüğ̈̈ Belirti Tarama Listesi anne-baba, çocuk ve öğretmen formları geçerlik güvenirlik çalışması, Unpublished manuscript, 
Department of Psychology, Ankara University, Ankara.

Feather, N. T., Woodyatt, L., \& McKee, I. R. (2012). Predicting support for social action: How values, justice-related variables, discrete emotions, and outcome expectations influence support for the Stolen Generations. Motivation and Emotion, 36(4), 516-528.

Fischer, R. (2004). Standardization to account for cross-cultural response bias: A classification of score adjustment procedures and review of research. Journal of Cross-Cultural Psychology, 35, 263-282.

Gallimore, R., Weisner, T. S., Kaufman, S. Z., \& Bernheimer, L. P. (1989). The social construction of ecocultural niches: family accommodation of developmentally delayed children. American Journal of Mental Retardation, 94, 216-30.

Garcia, F., \& Gracia, E. (2009). Is always authoritative the optimum parenting style? Evidence from Spanish families. Adolescence, 44(173), 101.

Goldstein, S. (2011). Learning disabilities in childhood. In Goldstein, S., Naglieri, J. A., \& DeVries, M. (Eds.), Learning and attention disorders in adolescence and adulthood: Assessment and treatment (pp. 31-58). New Jersey, NJ: John Wiley \& Sons, Inc.

Goodley, D. (2001). 'Learning difficulties', the social model of disability and impairment: Challenging epistemologies. Disability \& Society, 16(2), 207-231.

Goodwin, R., Costa, P., \& Adonu, J. (2004). Social support and its consequences: 'Positive' and 'deficiency'values and their implications for support and self-esteem. British Journal of Social Psychology, 43(3), 465-474.

Gottman, J. M., Katz, L. F., \& Hooven, C. (1996). Parental meta-emotion philosophy and the emotional life of families: Theoretical models and preliminary data. Journal of Family Psychology, 10, 243-268.

Green, E. G., Deschamps, J. C., \& Paez, D. (2005). Variation of individualism and collectivism within and between 20 countries a typological analysis. Journal of Cross-Cultural Psychology, 36(3), 321-339.

Greenham, S. L. (1999). Learning disabilities and psychosocial adjustment: A critical 
review. Child Neuropsychology, 5(3), 171-196.

Greenspan, N. L. (2004). Helplessness in parents of children with learning disabilities. Dissertation Abstracts International, 65, 2627.

Harry, B. (2002). Trends and issues in serving culturally diverse families of children with disabilities. The Journal of Special Education, 36(3), 131.

Hassall, R., Rose, J., \& McDonald, J. (2005). Parenting stress in mothers of children with an intellectual disability: The effects of parental cognitions in relation to child characteristics and family support. Journal of Intellectual Disability Research, 49(6), 405-418.

Hastings, R. P. (2002). Parental stress and behaviour problems of children with developmental disability. Journal of Intellectual and Developmental Disability, 27(3), 149-160.

Hayes, A. F. (2013). Introduction to mediation, moderation, and conditional process analysis: A regression-based approach. New York, NY: Guilford Press.

Heiervang, E., Stevenson, J., Lund, A., \& Hugdahl, K. (2001). Behaviour problems in children with dyslexia. Nordic Journal of Psychiatry, 55(4), 251-256.

Heiman, T., \& Berger, O. (2008). Parents of children with Asperger syndrome or with learning disabilities: Family environment and social support. Research in Developmental Disabilities, 29(4), 289-300.

Herring, S., Gray, K., Taffe, J., Tonge, B., Sweeney, D., \& Einfeld, S. (2006). Behaviour and emotional problems in toddlers with pervasive developmental disorders and developmental delay: Associations with parental mental health and family functioning. Journal of Intellectual Disability Research, 50(12), 874-882.

Hodapp, R. M., Dykens, E. M., \& Masino, L. L. (1997). Families of children with Prader-Willi syndrome: Stress-support and relations to child characteristics. Journal of Autism and Developmental Disorders, 27(1), 11-24.

Hooven, C., Gottman, J. M., \& Katz, L. F. (1995). Parental meta-emotion structure predicts family and child outcomes. Cognition \& Emotion, 9(2-3), 229-264.

Kağıtçıbaşı, Ç. (1996). Family and human development across cultures: A view from 
the other side. New Jersey, NJ: Psychology Press.

Kağıtçıbaşı, C., \& Ataca, B. (2005). Value of children and family change: A three-decade portrait from Turkey. Applied Psychology, 54(3), 317-337.

Kağıtçıbaşı, Ç. (2009). Family, self, and human development across cultures: Theory and applications. New Jersey, NJ: Psychology Press.

Kaner, S. (2003). Aile destek ölçeği: Faktör yapısı, güvenirlik ve geçerlik çalışmaları. Ankara Üniversitesi Eğitim Bilimleri Fakültesi Özel Ĕ̈itim Dergisi, 4(1), 57-72.

Kaner, S. (2004). Engelli çocukları olan ana babaların algıladıkları stres, sosyal destek ve yaşam doyumlarının incelenmesi. Final Report of Scientific Research Project, Ankara University, Ankara.

Kaner, S. (2007). Öğretmenlerin ve anne-babaların öz-yetkinlik inançları, tükenmişlik algıları ve çocukların problem davranışları. Ankara Üniversitesi Bilimsel Araştırma Projesi Raporlarl, Ankara University, Ankara.

Kaner, S., \& Bayrakl1, H. (2009). Zihinsel engelli ve engelli olmayan çocuklu annelerde y1lmazlık, sosyal destek ve stresle başa çıkma becerileri. Journal of Educational Sciences \& Practices, 8(15).

Karadă̆, G. (2009). Engelli çocuğa sahip annelerin yaşadıkları güçlükler ile aileden algıladıkları sosyal destek ve umutsuzluk düzeyleri. TAF Preventive Medicine Bulletin, 8(4), 315-322.

Kavale, K. A., \& Forness, S. R. (1996). Social skill deficits and learning disabilities: A meta-analysis. Journal of Learning Disabilities, 29(3), 226-237.

Keenan, T. \& Evans, S. (2009). An introduction to child development. (2nd ed.). London, LD: Sage Publications.

Kellegrew, D. H. (2000). Constructing daily routines: A qualitative examination of mothers with young children with disabilities. American Journal of Occupational Therapy, 54(3), 252-259.

Keogh, B. K., \& Weisner, T. (1993). An ecocultural perspective on risk and protective factors in children's development: Implications for learning disabilities. Learning Disabilities Research and Practice, 8(1), 3-10. 
Keogh, B. K., Gallimore, R., \& Weisner, T. (1997). A sociocultural perspective on learning and learning disabilities. Learning Disabilities Research and Practice, 12(2), 107-113.

Lancaster, P. E. (2001). Parenting children with learning disabilities. In Fine, M. J., \& Lee, S. W. (Eds), Handbook of Diversity in Parent Education (pp. 231-252). http://doi.org/10.1016/B978-012256483-3/50012-5

Lynch, E. W., \& Hanson, M. J. (1996). Ensuring cultural competence in assesment. In M. Mclean, D. B. Bailey Jr, M. Wolery (Eds.), Assesing infants and preschoolers with special needs (pp. 69-95). Merrill: Prentice Hall.

Lyon, G. R. (1996). Learning disabilities. The Future of Children, 54-76.

Lyytinen, H., Ahonen, T., Eklund, K., Guttorm, T. K., Laakso, M. L., Leinonen, S., ... Viholainen, H. (2001). Developmental pathways of children with and without familial risk for dyslexia during the first years of life. Developmental Neuropsychology, 20(2), 535-554.

Mccarty, C. A., Zimmerman, F. J., Digiuseppe, D. L., \& Christakis, D. A. (2005). Parental emotional support and subsequent internalizing and externalizing problems among children. Journal of Developmental \& Behavioral Pediatrics, 26(4), 267-275.

Michaels, C. R., \& Lewandowski, L. J. (1990). Psychological adjustment and family functioning of boys with learning disabilities. Journal of Learning Disabilities, 23(7), 446-450.

Miletic, A. (1986). The interpersonal values of parents of normal and learning disabled children. Journal of Learning Disabilities, 19(6), 362-367.

Morrison, G. M., \& Cosden, M. A. (1997). Risk, resilience and adjustment with learning disabilities. Learning Disability Quarterly, 20(1), 43-60.

Naglieri, J. A. \& Goldstein, S. (2011). Assessment of cognitive and neuropsychological processes. In Goldstein, S., Naglieri, J. A., \& DeVries, M. (Eds.), Learning and attention disorders in adolescence and adulthood: Assessment and treatment (pp. 137-159). New Jersey, NJ: John Wiley \& Sons, Inc. 
Nelson, J. M., \& Harwood, H. (2011). Learning disabilities and anxiety: A metaanalysis. Journal of Learning Disabilities, 44(1), 3-17.

Ngaujah, D. E. (2003). An eco-cultural and social paradigm for understanding human development: A (West African) context. Retrieved from http://citeseerx.ist.psu.edu/ viewdoc/download?doi=10.1.1.453.4689\&rep=rep1\&type $=$ pdf

Nihira K., Weisner T. S., Bernheimer L. P. (1994). Ecocultural assessment in families of children with developmental delays: construct and concurrent validities. American Journal on Mental Retardation, 98, 551-566.

Özkardeş, O. G. (2011). Türkiye'de özel öğrenme güçlüğüne ilişkin yapılan uygulamalar. Istanbul Ticaret Üniversitesi Sosyal Bilimler Dergisi. 21, 25-38.

Özsoy, A. S., Özkahraman, Ş., \& Çallı, F. (2006). Zihinsel Engelli Çocuk Sahibi ailelerin yaşadıkları güçlüklerin incelenmesi, Aile ve Toplum, 3(9), 24-26.

Pearson, V., \& Chan, T. W. (1993). The relationship between parenting stress and social support in mothers of children with learning disabilities: A Chinese experience [Abstract]. Social Science \& Medicine, 37(2), 267-274.

Phenice, L. A., Griffore, R. J., Hakoyama, M., \& Silvey, L. A. (2009). Ecocultural adaptive research: A synthesis of ecocultural theory, participatory research, and adaptive designs. Family and Consumer Sciences Research Journal, 37(3), 298309.

Prior, M., Smart, D., Sanson, A., \& Oberklaid, F. (1999). Relationships between learning difficulties and psychological problems in preadolescent children from a longitudinal sample. Journal of the American Academy of Child \& Adolescent Psychiatry, 38(4), 429-436.

Raghavan, R., \& Patel P. (2005). Learning disabilities and mental health: A nursing perspective (pp. 8-19). Blackwell Publishing.

Richards, C. M., Symons, D. K., Greene, C. A., \& Szuszkiewicz, T. A. (1995). The bidirectional relationship between achievement and externalizing behavior problems of students with learning disabilities. Journal of Learning Disabilities, $28(1), 8-17$.

Rohan, M. J., \& Zanna, M. P. (1996). Value transmission in families. In The Psychology 
of Values: The Ontario Symposium, 8, 253-276.

Rohner, R. P., \& Khaleque, A. (2003). Reliability and validity of the parental control scale: a meta-analysis of cross-cultural and intracultural studies. Journal of CrossCultural Psychology, 34, 643-649.

Rothman, H. R., \& Cosden, M. (1995). The relationship between self-perception of a learning disability and achievement, self-concept and social support. Learning Disability Quarterly, 18(3), 203-212.

Rudy, D., \& Grusec, J. E. (2001). Correlates of authoritarian parenting in individualist and collectivist cultures and implications for understanding the transmission of values. Journal of Cross-Cultural Psychology, 32(2), 202-212. doi:10.1177/0022022101032002007

Sagiv, L., \& Schwartz, S. H. (2000). Value priorities and subjective well-being: Direct relations and congruity effects. European Journal of Social Psychology, 30(2), 77-198.

Sandy, P. T., Kgole, J. C., \& Mavundla, T. R. (2013). Support needs of caregivers: Case studies in South Africa. International Nursing Review, 60(3), 344-350.

Santrock, J. W. (2009). Life-span development. Boston, MA: McGraw-Hill.

Schwartz, S. H., \& Bilsky, W. (1987). Toward a universal psychological structure of human values. Journal of Personality and Social Psychology, 53(3), 550-562.

Schwartz, S. H. (1990). Individualism-collectivism: critique and proposed refinements. Journal of Cross-Cultural Psychology. doi:10.1177/0022022190212001

Schwartz, S. H. (1992). Universals in the content and structure of values: Theoretical advances and empirical tests in 20 countries. Advances in Experimental Social Psychology, 25(1), 1-65.

Schwartz, S. (1999). A theory of cultural values and some implications for work. Applied Psychology. http://doi.org/10.1080/026999499377655

Schwartz, S. H., Melech, G., Lehmann, A., Burgess, S., Harris, M., \& Owens, V. (2001). Extending the cross-cultural validity of the theory of basic human values with a different method of measurement. Journal of Cross-Cultural Psychology. 
http://doi.org/10.1177/0022022101032005001

Schwartz, S. H., \& Bardi, A. (2001). Value hierarchies across cultures: Taking a similarities perspective. doi:10.1177/0022022101032003002

Schwartz, S. H., \& Boehnke, K. (2004). Evaluating the structure of human values with confirmatory factor analysis. Journal of Research in Personality.

doi:10.1016/S0092-6566(03)00069-2

Schwartz, S. H. (2006). Les valeurs de base de la personne: Théorie, mesures et applications [Basic human values: Theory, measurement, and applications]. Revue Française De Sociologie, 42, 249-288.

Schwartz, S. H., Cieciuch, J., Vecchione, M., Davidov, E., Fischer, R., Beierlein, C., ... \& Dirilen-Gumus, O. (2012). Refining the theory of basic individual values. Journal of Personality and Social Psychology, 103(4), 663.

Schwartz, S. (2013). Value priorities and behavior: Applying. In The Psychology of Values: The Ontario Symposium, 8, Psychology Press.

Skinner, D., \& Weisner, T. S. (2007). Sociocultural studies of families of children with intellectual disabilities. Mental Retardation and Developmental Disabilities Research Reviews. http://doi.org/10.1002/mrdd.20170.

Super, C. M., \& Harkness, S. (1986). The developmental niche: A conceptualization at the interface of child and culture. International Journal of Behavioral Development, 9(4), 545-569.

T. C. Milli Eğitim Bakanlığı. (2007). Çocuk gelişimi ve eğitimi: Öğrenme güçlüğü. Retrieved from http://mebk12.meb.gov.tr/meb iys_dosyalar/54/01/970767/dosyalar/2014_12/26043028_renmegl.pdf

Tak, Y. R., \& McCubbin, M. (2002). Family stress, perceived social support and coping following the diagnosis of a child's congenital heart disease. Journal of Advanced Nursing, 39(2), 190-198.

Tamis-LeMonda, C. S., Way, N., Hughes, D., Yoshikawa, H., Kalman, R. K., \& Niwa, E. Y. (2008). Parents' goals for children: The dynamic coexistence of individualism and collectivism in cultures and individuals. Social Development, 
17(1), 183-209.

Tetlock, P. E. (1986). A value pluralism model of ideological reasoning. Journal of Personality and Social Psychology, 50(4), 819.

Tews, L., \& Merali, N. (2008). Helping Chinese parents understand and support children with learning disabilities. Professional Psychology: Research and Practice, 39(2), 137-144.

Triandis, H. C., Leung, K., Villareal, M. J., \& Clack, F. I. (1985). Allocentric versus idiocentric tendencies: Convergent and discriminant validation. Journal of Research in Personality, 19(4), 395-415.

Triandis, H. C. (1993). Collectivism and individualism as cultural syndromes. CrossCultural Research, 27(3-4), 155-180.

Trommsdorff, G., \& Kornadt, H. J. (2003). Parent-child relations in cross-cultural perspective. Handbook of Dynamics in Parent-child Relations, 271-306.

Tudge, J. R., Hogan, D. M., Snezhkova, I. A., Kulakova, N. N., \& Etz, K. E. (2000). Parents' child-rearing values and beliefs in the United States and Russia: The impact of culture and social class. Infant and Child Development, 9(2), 105-121.

Undheim, A. M. (2003). Dyslexia and psychosocial factors. A follow-up study of young Norwegian adults with a history of dyslexia in childhood. Nordic Journal of Psychiatry, 57(3), 221-226.

Undheim, A. M., Wichstrøm, L., \& Sund, A. M. (2011). Emotional and behavioral problems among school adolescents with and without reading difficulties as measured by the youth self-report: A one-year follow-up study. Scandinavian Journal of Educational Research, 55(3), 291-305.

Wagner, M. M., \& Blackorby, J. (1996). Transition from high school to work or college: How special education students fare. The Future of Children, 103-120.

Waggoner, K., \& Wilgosh, L. (1990). Concerns of families of children with learning disabilities. Journal of Learning Disabilities, 23(2), 97-98.

Weisner, T. S. (1997). The ecocultural project of human development: Why 
ethnography and its findings matter. Ethos, 25(2), 177-190.

Weisner, T. S. (1998). Human development, child well-being, and the cultural project of development. New Directions for Child Development, 81, 69-85.

Weisner T. S. (2002a). Ecocultural understanding of children developmental pathways. Human Development, 45(4), 275-281.

Weisner, T. S. (2002b). Essay review making a good thing better: ways to strengthen sociocultural research in human development essay review of children's engagement in the world: Sociocultural perspectives by Artin Göncü. Human Development, 45, 372-380.

Weisner, T. S. (2009). Culture, development, and diversity: Expectable pluralism, conflict, and similarity. Ethos. doi.org/10.1111/j.1548-1352.2009.01037.x

Wenz-Gross, M., \& Siperstein, G. N. (1998). Students with learning problems at risk in middle school: Stress, social support, and adjustment [Abstract]. Exceptional Children, 65(1), 91.

Williamson, E. A., \& Slye, G. L. (2002). Developmental pathways and technology: The foundations of enhanced intellectual excellence. Retrieved from http://eric.ed.gov/?id=ED464633 


\title{
APPENDICES
}

\section{Appendix1. Ethical Permission Form}

Fakülteniz Psikoloji Bölümü araștırma görevlilerinden Suzan ÇEN'in Öğr. Gör. Dr. A. Berna AYTAÇ sorumluluğunda yürüttüğü "Ekokültürel Bakışla Öğrenme Güçlüğü: Ailenin Destek Kaynakları, Değerler, Ebeveyn-Çocuk İlişkisi’’ başlıklı tez çalışması, Üniversitemiz Senatosu Etik Komisyonunun 04 Ağustos 2015 tarihinde yapmış olđuğu toplantıda incelenmiş olup, etik açıdan uygun bulunmuştur.

Bilgilerinizi rica ederim.

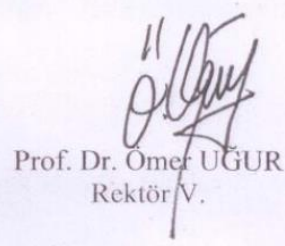

Ek: Tutanak 


\section{Appendix2. Dissertation Originality Report}

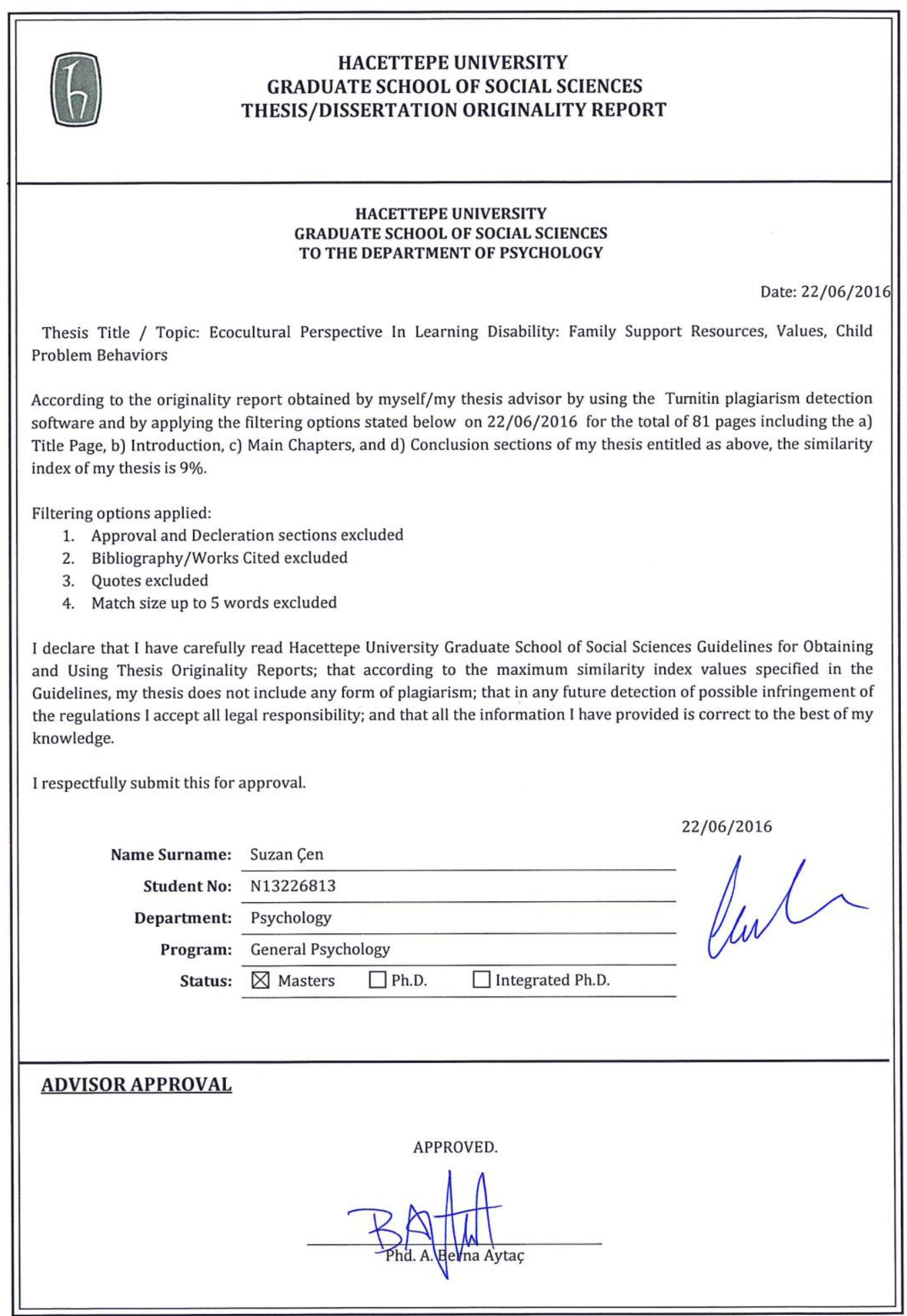




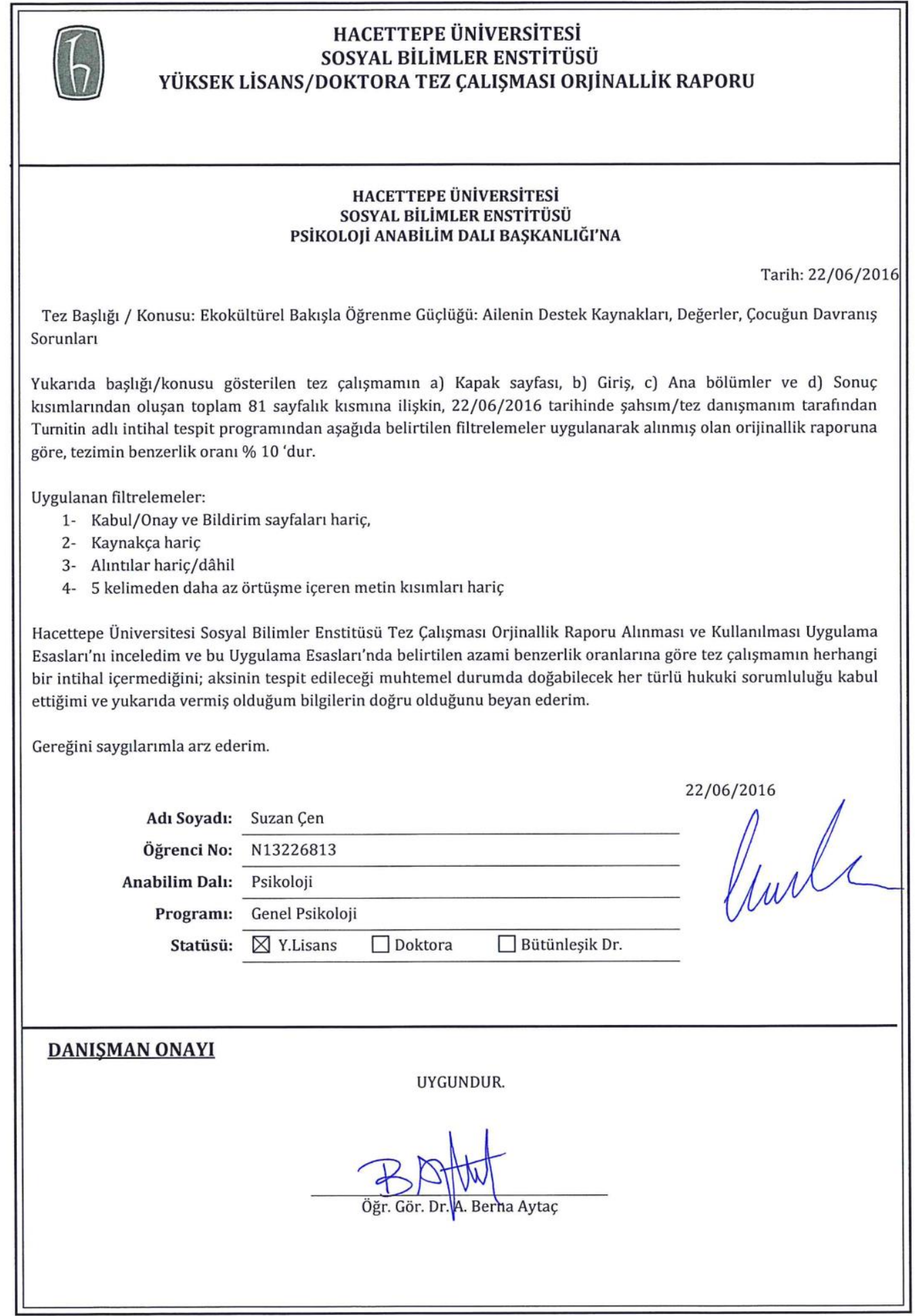

